\title{
Magnetic susceptibility variations in Upper Pleistocene deep-sea sediments of the NE Atlantic: Implications for ice rafting and paleocirculation at the last glacial maximum
}

\author{
Simon G. Robinson ${ }^{1}$ \\ Department of Earth Sciences, University of Cambridge, Cambridge, England \\ Mark A. Maslin² \\ Subdepartment of Quaternary Research, University of Cambridge, Cambridge, England

\section{Nicholas McCave} \\ Department of Earth Sciences, University of Cambridge, Cambridge, England
}

\begin{abstract}
Magnetic susceptibility (MS) variations are used to intercorrelate 17 Upper Pleistocene sediment cores taken from the NE Atlantic, between $40^{\circ}$ and $60^{\circ} \mathrm{N}$. The MSbased correlation depends on regionally consistent patterns of variation in the deposition of ice-rafted detritus (IRD) in response to Pleistocene glaciations, and especially to highfrequency ice-rafting episodes referred to in recent studies as "Heinrich events." The sedimentological and rock-magnetic basis for the apparent relationship between the MS signal and IRD content of NE Atlantic sediments is examined by (1) comparing the MS profiles of selected cores with their records of coarse fraction $(>150 \mu \mathrm{m})$ lithic fragment abundance and Neogloboquadrina pachyderma (sin) percentages, and (2) normalizing MS by expressing it both on a carbonate-free basis, and as a quotient with anhysteretic remanent magnetization (a parameter sensitive to magnetic mineral grain size variations). These comparisons show that variations in bulk-sediment MS are only partly driven by simple carbonate dilution ( \pm productivity and dissolution) effects. Changes in both the concentration and grain size of magnetic minerals within the lithogenic noncarbonate fraction also impose a significant influence on bulk MS values. In particular, horizons rich in IRD are associated with significant increases in the relative proportion of coarse grained (multidomain) ferrimagnetic particles in the sediment. This is because ice-rafting, in contrast to most other mechanisms capable of transporting detrital magnetic minerals to pelagic environments, has a high potential for delivering large ferrimagnetic grains as components of sand-sized, polycrystalline lithic fragments. This fundamental linkage between the IRD content and MS signal of NE Atlantic sediments is used to reconstruct the patterns of variation in IRD deposition and, by inference, surface currents of the last glacial maximum (LGM, $\sim 18-19 \mathrm{ka}$ ) relative to the present-day NE Atlantic, using the time-slice mapping approach developed by the CLIMAP project group. Our LGM/Holocene MS ratio map, based on sample pairs from over 80 deep-sea cores, confirms that there was a weak, cyclonic gyre north of the polar front in the LGM North Atlantic. The gyre comprised a sluggish warm current in the NE Atlantic flowing north between latitudes $47^{\circ}$ and $62^{\circ} \mathrm{N}$, partly fed by subtropical waters from south of the polar front, and carrying large numbers of icebergs derived from several sources, most of which melted between Latitudes $45^{\circ}$ and $52^{\circ} \mathrm{N}$. The warm current probably continued its flow into the Iceland Basin, where it fed into a south-flowing current which transported melting icebergs from Iceland and Scandinavia along the western flank of the Reykjanes Ridge.
\end{abstract}

\footnotetext{
${ }^{1}$ Now at Department of Environmental and Geographical Sciences, Manchester Metropolitan University, Manchester, England.

${ }^{2}$ Now at Department of Geography, University College London, London, England.
}

Copyright 1995 by the American Geophysical Union.

Paper number 94PA02683.

0883-8305/95/94PA-02683\$10.00

\section{Introduction}

In a study which set out to refute theories linking climatic change to secular variation of the earth's magnetic field, Kent [1982] demonstrated that the intensity of natural remanent magnetization (NRM) of deep-sea sediments, like magnetic susceptibility (MS) and other rock-magnetic properties, varies mainly according to changes in lithology. That lithological variations of late Cenozoic deep-sea 
sediments may be climatically controlled is well established [e.g., Bradley et al., 1941; Olausson, 1967; Broecker, 1971; Berger, 1973], and the mechanisms responsible, like carbonate dissolution, productivity changes, and dilution by terrigenous detritus, have been studied in detail [e.g., Volat et al., 1980; Crowley, 1985; Peterson and Prell, 1985; Dean and Gardner, 1986; Rea et al., 1986; Chuey et al., 1987; Farrell and Prell, 1989; Diester-Haass, 1991; Grötsch et al., 1991]. Kent's study thus led the way for others to begin using MS and other rock-magnetic parameters as simple and rapid tools for reconstructing the paleoenvironmental records of deep-sea sediments [Robinson, 1982; Bloemendal, 1983; Robinson and Bloemendal, 1983; Oldfield and Robinson, 1985]. The potential stratigraphic value of logging MS variations in deep-sea cores had already been noted in much earlier studies [e.g., Radhakrishnamurty et al., 1968; Amin et al., 1972; Somayajulu et al., 1975]. In more recent paleoceanographic studies [Robinson, 1986a, 1986b, Mead and Tauxe, 1986; Bloemendal et al., 1988; Doh et al., 1988; Hall and King, 1989; Hall et al., 1989a, b; Bloemendal et al., 1989, 1992; Sager and Hall, 1990], it has become clear that climatically-induced, lithologically-modulated variations in the amount of magnetic material in deep-sea sediments are also often paralleled by changes in the composition (mineralogy and/or grain size) and concentration of magnetic mineral assemblages within the lithogenic fraction of the sediment. Such variations are often associated with changes in the source of magnetic mineral input linked to changes in the provenance and/or delivery mechanisms of terrigenous detritus. Magnetic parameters, especially MS, have thus become recognized as effective tools for monitoring variations in the supply of terrigenous sediment to the oceans in response to late Cenozoic climatic changes, notably in studies of aeolian influx downwind from major continental deserts [e.g., Bloemendal and deMenocal, 1989; deMenocal et al., 1991; Clemens and Prell, 1991; Bloemendal, 1993].

In the North Atlantic, deposition of glacigenic detritus from the base of melting icebergs is by far the most important mechanism for supplying terrigenous sediment to pelagic areas, and is linked directly to climatic oscillations [Bramlette and Bradley, 1941; Conolly and Ewing, 1965; Ruddiman and Glover, 1972; Ruddiman and McIntyre, 1973, 1976, 1981; Ruddiman, 1977a, 1977b, Kolla et al, 1979; Fillon et al., 1981; Molnia, 1983; Zimmerman et al., 1984; Fillon, 1985; Smythe et al., 1985; Heinrich, 1988; Bond et al., 1992; Broecker et al., 1992; Grousset et al., 1993; Alley and MacAyeal, 1994]. During Pleistocene cold stages, more than half of the entire glaciated area of the world (including Antarctica) drained into the North Atlantic [Flint, 1971], and up to $40 \%$ of the total sediment deposited there was transported to its site of deposition by ice-rafting [Molnia, 1983]. Many of the glaciated source regions for the ice-rafted detritus (IRD) deposited in the North Atlantic contain frequent outcrops of basic igneous rocks or their sedimentary derivatives. For example, there are the Tertiary igneous provinces of Iceland and Greenland (east and west coasts); the Precambrian gneisses of the Canadian Shield; and the Caledonian volcanics, volcaniclastics and metasediments of the Appalachians, Nova Scotia, Scotland, and Scandinavia. Glacigenic detritus from these sources often contains primary, unaltered ferrimagnetic (i.e., magnetite-type) minerals as minor or trace components (e.g., often as exsolved inclusions in grains of plagioclase feldspar or other mafic minerals [Haggerty, 1976a, b]) in physically weathered and comminuted, but chemically stable rock flour [Thompson and Oldfield, 1986, p. 65; Gale and Hoare, 1991, p. 208].

The dependence of the MS signal of Pleistocene NE Atlantic sediments on IRD imput was first noted by Robinson [1986a], who observed that glacial horizons of cores from the King's Trough Flank area, northeast of the Azores (Figure 1), were not only characterised by generally higher WCMS values than those of interglacial horizons, but that variations in WCMS within glacial horizons could be attributed to individual ice-rafting episodes. In a later paper, Robinson [1990, p. 760] further suggested that the WCMS peaks in glacial horizons of his King's Trough Flank cores correlated with the intervals of high ice-rafted sand input identified by Heinrich [1988] in cores from the nearby Dreizack Seamount area (Figure 1). We attempt to confirm the validity of this suggested correlation below. These North Atlantic ice-rafting episodes were subsequently termed "Heinrich events" by Broecker et al. [1992], though in fact their existence was recognized in earlier studies [e.g., Fillon et al., 1981; Fillon, 1985]. Recently, Grousset et al. [1993] used WCMS profiling to identify and correlate between Heinrich events in 20 late Pleistocene deep-sea cores, and to map the spatial distribution of these IRD layers in the NE Atlantic between $40^{\circ}$ and $55^{\circ} \mathrm{N}$.

In the present study, we also use MS variations to correlate between a number of IRD events in 17 NE Atlantic cores (between $40^{\circ}$ and $60^{\circ} \mathrm{N}$ ), and to reconstruct the patterns of variation in IRD deposition in this region at the LGM ( 18-19 ka), as inferred by the differences in MS between samples representing the LGM and recent Holocene in more than 80 deep-sea cores taken from between $35^{\circ}$ and $70^{\circ} \mathrm{N}$ (Table 1). The aim of the study is to show why MS variations of deep-sea sediments in the NE Atlantic (at least) can be used to monitor changes in the deposition of IRD, and then to demonstrate how such information can be used to reconstruct iceberg dispersal paths and, by inference, the paleocirculation patterns of the glacial North Atlantic.

\section{Materials and Methods}

\section{Location of Cores and Time-Slice Sample Sites}

This study is based on two types of paleoceanographic information: (1) continuous stratigraphic (time-series) variation of magnetic and sedimentological properties of 17 deep-sea cores (Figure 1, Table 1); and (2) variations in MS of two sets of isochronous (time-slice), samples taken from a further 64 cores, augmented by MS data from the equivalent horizons in the 17 cores examined here (Figure 1, Table 1). The time slices chosen for study are the LGM $(\sim 18-19$ ka) and the "recent" Holocene, thus allowing us to derive the ratio of the glacial MS value to that of the present-day, or recent value.

\section{Cores, Sampling, and Whole-Core Measurements}

The King's Trough Flank gravity cores (S8-79-1 to -8) and piston cores (82-PCS-01 \& 04) were obtained by the 


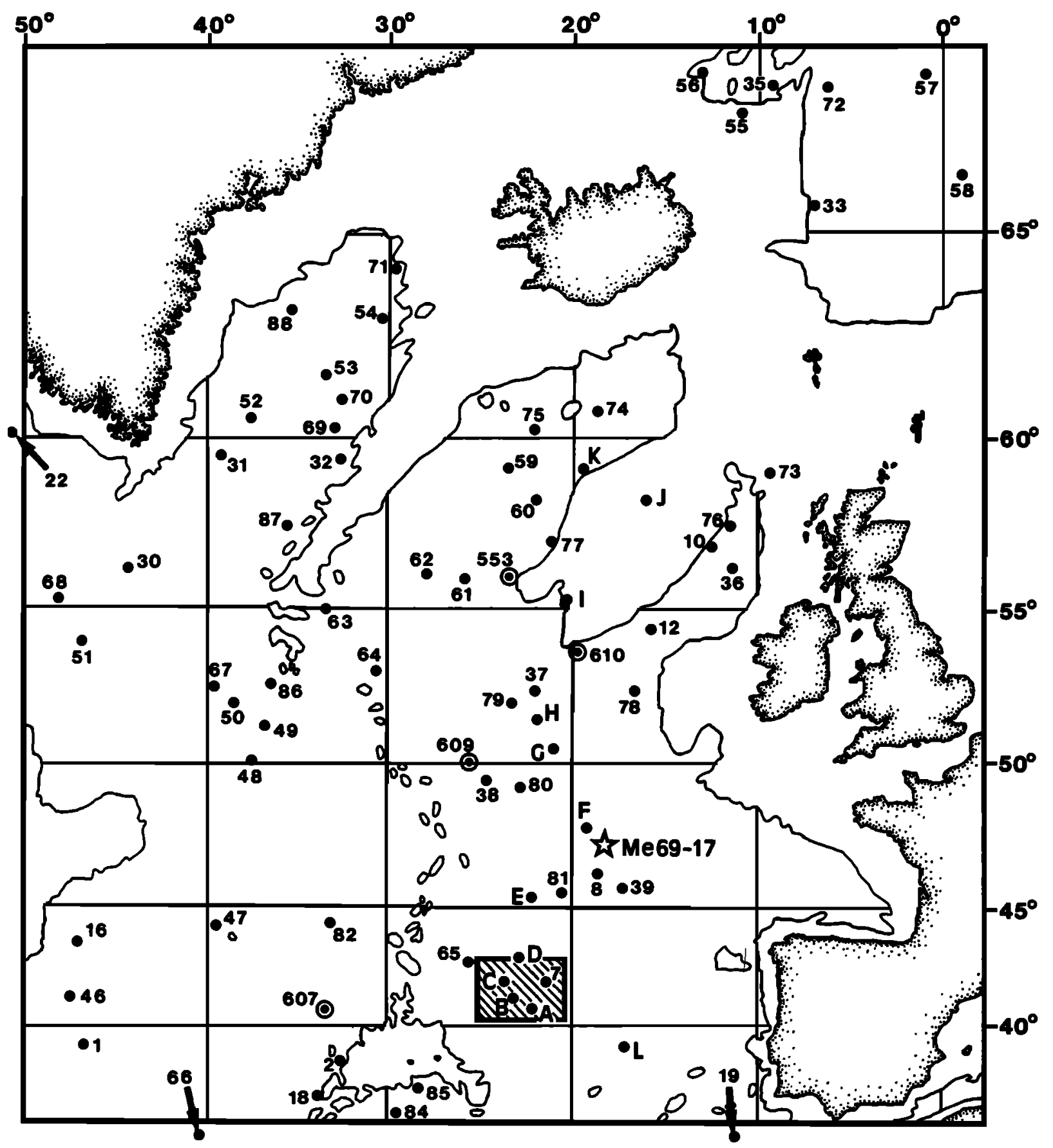

Figure 1. Location of coring stations in the NE Atlantic (see Table 1 for position and water depth). Sites from which the cores used in this study were obtained are indicated by the letters A - J, and/or are enclosed within the shaded area (King's Trough Flank). DSDP sites are indicated by a circled dot, with the corresponding site number (downhole data from sites 553 and 610 are shown in Figure 5, and time-slice data from sites 607 and 609 are used in compiling Figure 12). Time-slice sample sites from the study by Zimmerman [1982] are numbered according to the scheme used in the original study. The star indicates the location of Heinrich's core Me69-17 from the Dreizack Seamount area. Continental margins and oceanic ridges are delineated by 1000 Fathom isobath.

U.K. Institute of Oceanographic Sciences (IOS) and Dutch Geological Survey, respectively [Kidd et al., 1983]. The Kasten core D9812 was also taken by the IOS. These cores are stored at the IOS core repository, where whole-core measurements of volume MS were performed on split-core archive sections at 2-cm intervals, and samples were taken at the same intervals from the gravity and Kasten cores for laboratory measurements of mass-specific MS (and other 
Table 1. Position and Water Depth of Coring Stations From Which Cores or Time-Slice Samples Used in this Study Were Obtained

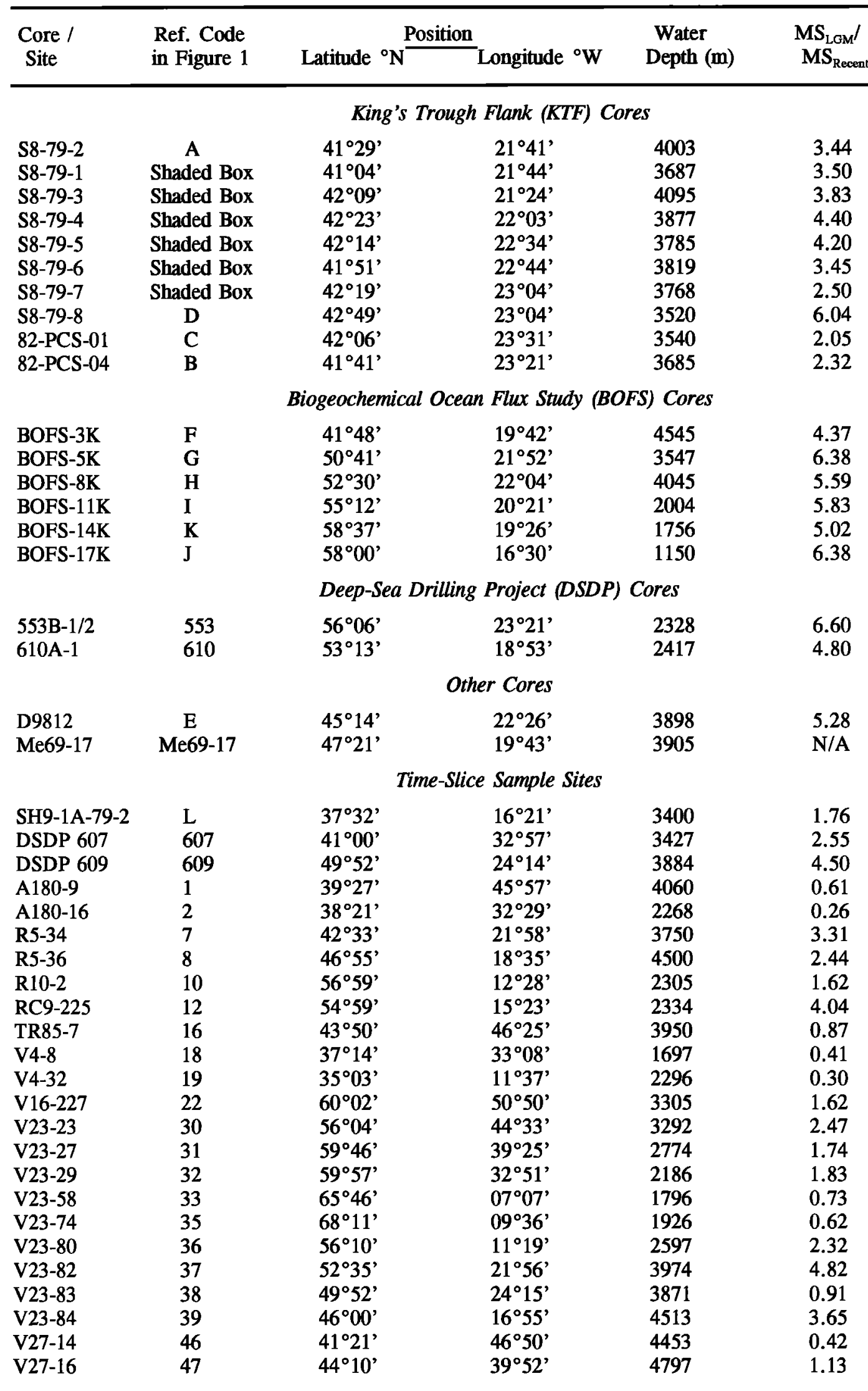


Table 1. (Continued)

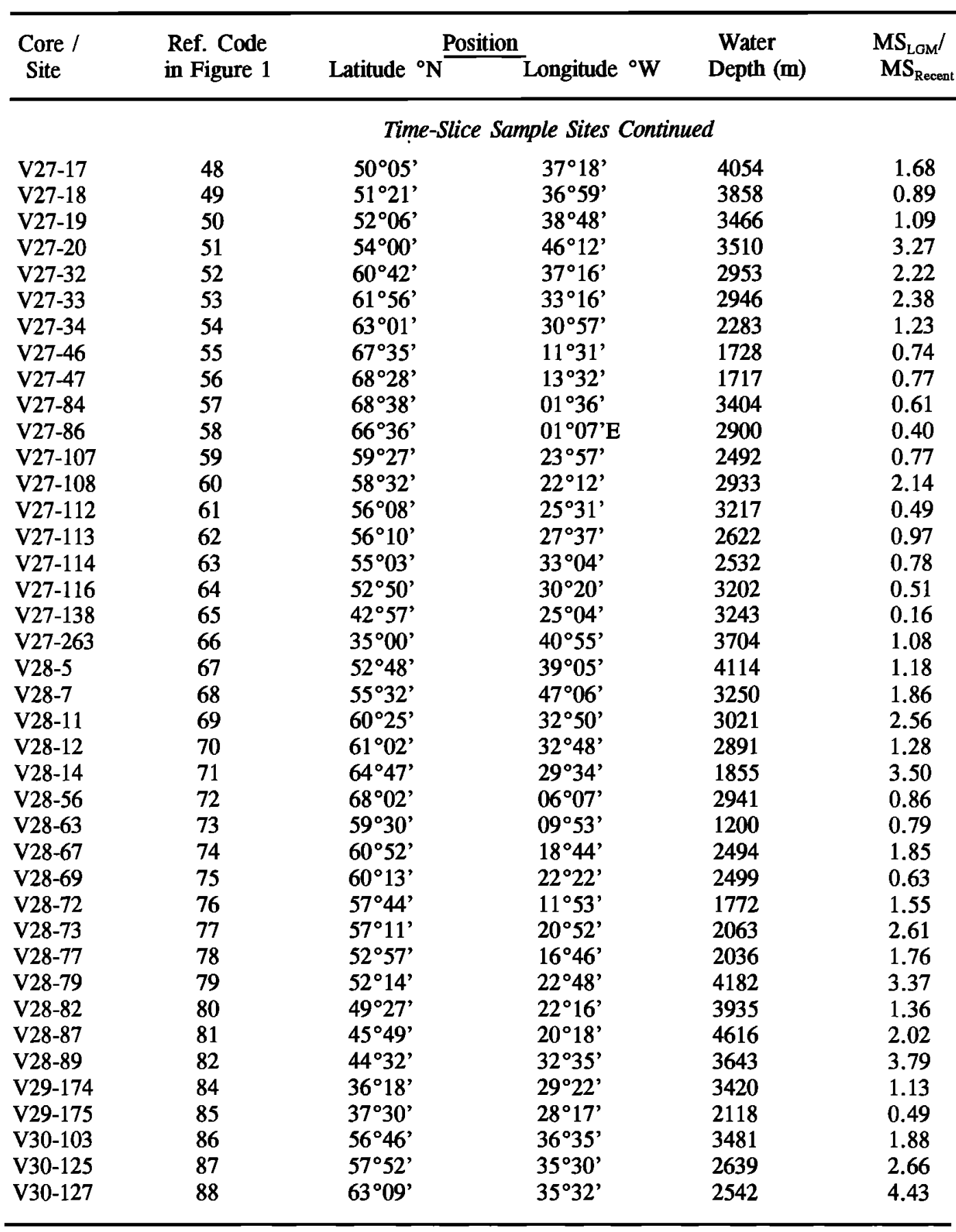

Also listed are the LGM/Holocene MS-ratios for each site, as used to compile the map shown in Figure 12 below.

sediment and magnetic properties) made on air-dried, disaggregated powders. The Kasten cores BOFS-3K to $17 \mathrm{~K}$ were obtained on RRS Discovery Cruise 184: the third cruise of the Biogeochemical Ocean Flux Study (BOFS) [McCave, 1989], with WCMS measurements at 2-cm intervals being made on board ship. Measurements of WCMS were made at 3- or 5-cm intervals on split-core archive sections of Deep-Sea Drilling Project (DSDP) cores from holes 553B and 610A stored at the Ocean Drilling Program's (ODP) core repository at Lamont-Doherty Geological Observatory. Time-slice WCMS data from DSDP sites 607 and 609 were provided by John King and coworkers from the University of Rhode Island. Core SH91A-79-2 was taken by the Universities of Liverpool and Leeds, with MS data obtained on air dried, powdered samples taken at 2 -cm intervals [Robinson, 1986b]. All 
remaining time-slice samples were provided by $R$. Chester, University of Liverpool, and were obtained for a study by Zimmerman [1982] which was based largely on the same cores, and sampling horizons, as were used by the CLIMAP project [McIntyre et al., 1976]. Mass-specific MS measurements of these samples were made on air-dried, disaggregated powders.

\section{Magnetic Susceptibility Measurements}

Whole-core measurements of volume magnetic susceptibility $(\kappa)$ were made using a Bartington Instruments' hand-held ferrite-probe (F-probe) type MS2 sensor connected to a standard, Bartington MS2 meter, also used later for discrete sample measurements of mass-specific MS $(\chi)$. The Bartington MS system is based on the principle used in metal detectors [Lancaster, 1966], and is described in more detail by Robinson [1990, 1993]. The F-probe sensor was designed specifically for logging MS variations of sedimentary sections or soils in the field, but can be used to measure split-core sections in core repositories. The spatial resolution of this instrument $(\sim 1.5 \mathrm{~cm})$ is much higher than that of the pass-through loop-type of MS sensor generally used for whole-round core logging on-board ship (e.g., by the ODP), and individual measurements can be more accurately driftcorrected by taking background readings in between core measurements. The signal-to-noise ratio of the F-probe sensor is approximately $1 \times 10^{-6}$ dimensionless S.I. units (or
$1 \times 10^{-7}$ c.g.s. units, nominally $\mathrm{G}^{-} \mathrm{e}^{-1} \mathrm{~cm}^{-3}$ ) when used in standard, rapid scanning mode. For measurements made core repositories, however, it is possible to improve the noise level by one order of magnitude, by switching the Bartington meter to the sensitivity range designed for discrete sample measurements of mass-specific MS. Variations in whole-core volume MS $(\kappa)$ are controlled by the concentration, mineralogy and grain size (domain configuration) of magnetic minerals in the sediment (usually present only in trace quantities in most pelagic sediments, i.e., $<0.1$ per mil); by the concentration and type of paramagnetic $\left(\mathrm{Fe}^{2+}, \mathrm{Fe}^{3+}\right.$, and $\mathrm{Mn}^{2+}$ bearing) clay, or labile minerals in the sediment when magnetic mineral concentration is very low (i.e., $<0.01$ per mil); and by the void ratio of the sediment.

Laboratory-based measurements of mass-specific MS $(\chi)$ were made on dried, disaggregated samples packed firmly into $10 \mathrm{~cm}^{3}$ cylindrical plastic sample holders, and weighed to $0.001 \mathrm{~g}$. Measurements of $\chi$ were made with a Bartington Instruments' discrete sample solenoid-type MS2 sensor, calibrated to measure $10 \mathrm{~cm}^{3}$ cylindrical samples, and connected to the same Bartington MS2 meter as used earlier for WCMS measurements. The calibration-volume sample MS values are simply expressed per unit mass of dry sediment. For discrete sample $\chi$ measurements, the Bartington system has a noise level of about $1 \times 10^{-9}$ S.I. units $\left(\mathrm{m}^{3} \mathrm{~kg}^{-1}\right)$ or about $5 \times 10^{-8}$ c.g.s. units $\left(\mathrm{G} . \mathrm{Oe}^{-1} \mathrm{~cm}^{-3} \mathrm{~g}^{-1}\right)$. Massspecific MS variations are controlled by the same factors as

\section{KING'S TROUGH FLANK GRAVITY CORES: Sp. Magnetic Susceptibility ( $\chi$, in 10*E-5 S.I. units)}

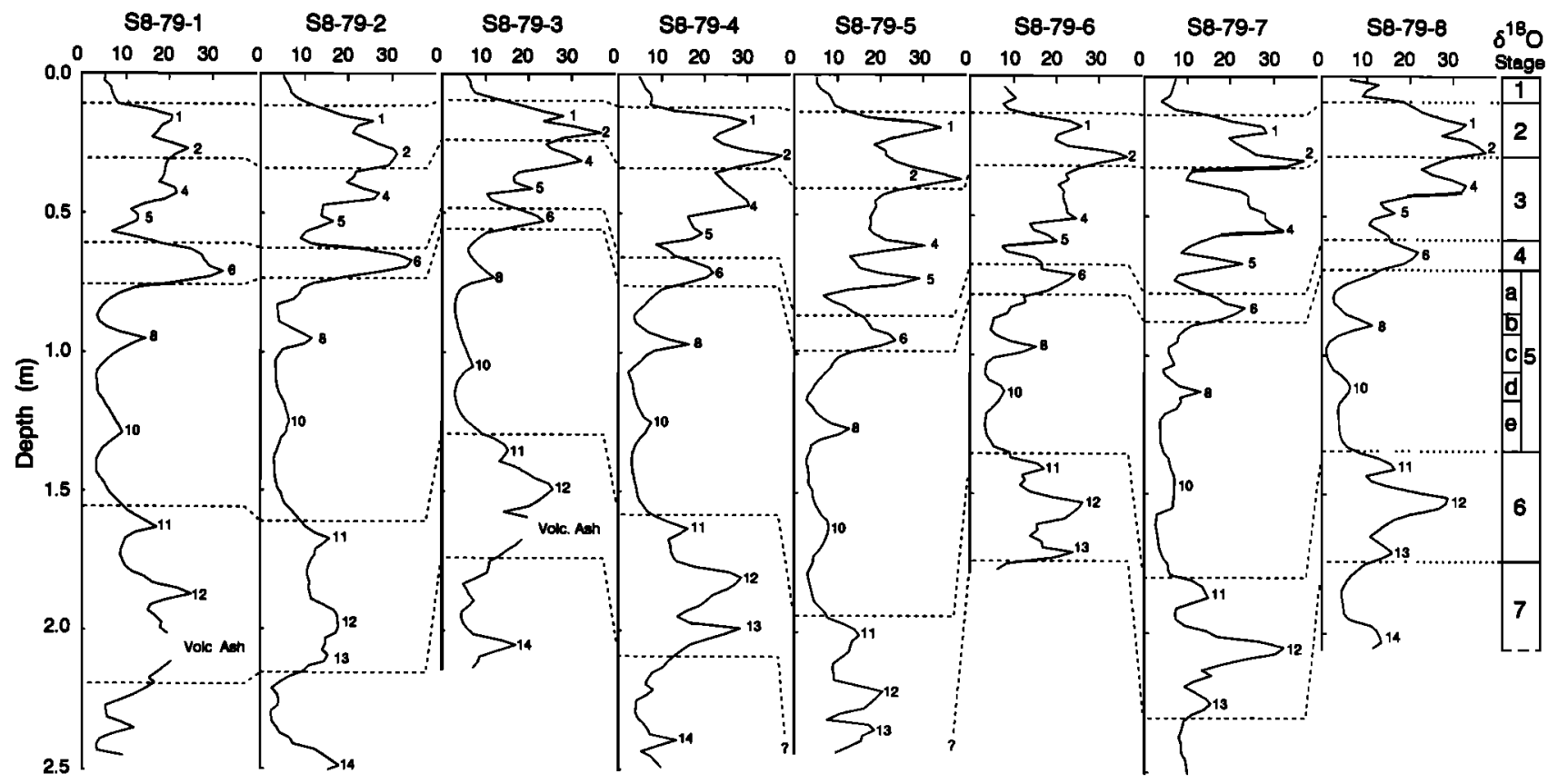

Figure 2. Discrete sample, mass-specific magnetic susceptibility $(\chi)$ profiles of the King's Trough Flank gravity cores (sampled at $2-\mathrm{cm}$ intervals). Correlation lines connect isotopic stage boundaries in the cores identified by $\delta^{18} \mathrm{O}$ analyses of $\boldsymbol{G}$. bulloides specimens in samples taken at $5-$ or $10-\mathrm{cm}$ intervals in all eight cores [Weaver, 1983]. Numbered MS peaks are correlative and correspond to regional ice-rafting episodes, as identified by Heinrich [1988] in cores from the Dreizack Seamount area (see Figure 1). MS data from horizons rich in local volcanic ash (tephra from the Azores, or seamounts within the King's Trough Flank area) are not plotted. The MS signal of these horizons is much stronger than that of the ambient glacial sediment, and would be deflected off scale in this figure. 
those noted above for whole-core volume MS, except that instead of void ratio, the rational basis of the parameter is the average specific gravity (not the dry bulk density) of the sediment.

\section{Anhysteretic Magnetic Remanence (ARM) and the MS/ARM Quotient}

Measurements of anhysteretic remanent magnetization (ARM) were made on samples from two cores in this study, S8-89-4 and D9812, in order to illuminate variations, if any, in the grain size of magnetic mineral components within the sediment. Such variations may impose a secondary influence on the MS of samples, the principal influence being the concentration of magnetic (especially ferrimagnetic) minerals. Since both ARM and MS are partially dependent on magnetic mineral concentration, this common factor may be normalized by expressing the two magnetic parameters in the form of a quotient, which thus reflects variations in the secondary influences on the response of ARM and MS to sample magnetic assemblages.

In this study, ARMs were imparted to samples (subsequent to MS measurements) by placing them in a peak-a.c. demagnetizing field of $100 \mathrm{mT}$, with a superimposed d.c. field set to $0.04 \mathrm{mT}$, applied parallel to the demagnetization axis. ARM measurements were made with a computerized parastatic magnetometer system in the Subdepartment of Geophysics, University of Liverpool, U.K. This instrument has a noise level of about $1 \times 10^{-7}$ S.I. units $\left(\mathrm{A} \mathrm{m}^{2} \mathrm{~kg}^{-1}\right)$ (and the same in c.g.s. units, $\mathrm{G} \mathrm{cm}^{-3} \mathrm{~g}^{-1}$ ). The mass specific ARM values of samples are here expressed as anhysteretic susceptibilities $\left(\chi_{\text {ARM }}\right)$, that is, as a function of the strength of the applied d.c. biasing field, in units of magnetization per unit of magnetic field (rationalized in the S.I. system to $\mathrm{m}^{3} \mathbf{k g}^{-1}$ ).

Within the range of magnetic grain sizes above the threshold for superparamagnetic (SPM) behaviour (i.e., $>0.03 \mu \mathrm{m}$ in pure magnetite, or $\sim 0.08 \mu \mathrm{m}$ in equidimensional titanomagnetite [Dunlop, 1981]), MS varies as a function of magnetic grain size in the opposite manner to ARM. For example, O'Reilly [1984, p. 144], in comparing the results from a variety of experimental rock-magnetic studies reported in the literature, showed that in all cases the room temperature MS of (titano)magnetite assemblies increased uniformly with grain size in the $1-100 \mu \mathrm{m}$ range, but varied little, and was at its lowest, in the $\langle 1 \mu \mathrm{m}$ range. In contrast, ARM is highest for magnetic grains in the size range between the SPM boundary and $0.1 \mu \mathrm{m}$, above which ARM declines logarithmically, and is thus relatively insensitive to changes in grain size throughout the $1-100 \mu \mathrm{m}$ range [Maher, 1988]. Ultrafine magnetic particles which are marginally smaller than the $0.03 \mu \mathrm{m}$ SPM threshold grain size are incapable of retaining a remanent magnetization like ARM, but exhibit extremely high MS values. The presence of these so-called "viscous" SPM grains in the magnetic mineral fractions of sediments will exert a disproportionately strong influence on their bulk MS values, thus complicating the interpretation of MS/ARM variations [King et al., 1982]. In such circumstances, consideration of interremanence quotients like ARM/IRM (isothermal remanence), which are not influenced by viscous-SPM effects, may be required in order to assess trends in grain size among the stable (nonviscous) magnetic mineral particles in the sediment.

\section{Coarse Fraction Composition}

In two of the BOFS cores, $5 \mathrm{~K}$ and $8 \mathrm{~K}$, the relative abundance of lithic fragments and whole specimens of leftcoiling Neogloboquadrina pachyderma were estimated in samples taken at $2-\mathrm{cm}$ intervals. Grain counts were made in subsamples which contained at least 300 whole foraminifera specimens separated from the $>150 \mu \mathrm{m}$ fraction.

After dispersion in distilled water, bulk samples were wetsieved through a $150-\mu \mathrm{m}$ screen, and the residues washed, then oven dried at $60^{\circ} \mathrm{C}$ and weighed (to $0.001 \mathrm{~g}$ ). Coarse fractions were subsampled using a Soiltest CL-242A $>150$ $\mu \mathrm{m}$ sample divider, with the splitting procedure repeated until a subsample containing $\geq 300$ foraminifera specimens was obtained. These were examined under a binocular microscope, and the numbers of lithic grains relative to whole, or nearly whole foraminifera and foraminiferal fragments were counted (no biogenic silica grains were observed in the coarse fractions of either of these cores). The lithic fragment abundance (LFA) percentage was obtained by the relation:

$$
\mathrm{LFA} \%=\mathrm{LF} /(\mathrm{LF}+\mathrm{WF}+\mathrm{FF} / 4) \times 100
$$

where LF is the number of lithic fragments, WF is the number of whole foraminifera, and FF is the number of foraminiferal fragments (4 is a fragmentation factor: i.e., $\sim 4$ foraminiferal fragments equate with one in tact foraminiferal test). In addition, 16 species of planktonic foraminifera were identified and counted, of which the relative abundance of $N$. pachyderma (sin), expressed as a percentage of the total number of whole foraminifera, is reproduced here to indicate intervals of the cores characterised by a polar planktonic foraminiferal fauna which is dominated by this species [Kipp, 1976; McIntyre et al. 1976].

\section{Carbonate Content}

Carbonate content data are available for most of the cores used in this study [Weaver, 1983; Kidd et al., 1983; Robinson, 1986b; Manighetti, 1993]. Here we have reproduced only a selection of such data as required to compare with the results of magnetic measurements, or to express magnetic data on a carbonate free basis. Calcimetric data on cores S8-79-4 and D9812 were obtained on samples taken at 2 and $5 \mathrm{~cm}$ intervals, respectively, combining data from IOS sources obtained using the carbonate bomb device [Müller and Gastner, 1971; Dunn, 1980], with data obtained for the present study using the Chittick gasometric apparatus [Dreimanis, 1962], based on a method outlined by Bascomb [1974]. The results obtained by each of these techniques were reproducible to within a range of about $\pm 1 \% \mathrm{CaCO}_{3}$ equivalent. Carbonate content data on core 82-PCS-01 are from Kidd et al. [1983], and were obtained using a LECO carbon analyser [Boyce and Bode, 1972].

\section{Oxygen Isotope Ratios}

Oxygen isotope profiles (and other stratigraphic data) are also available for most of the cores used in this study [e.g., 
Weaver, 1983; Kidd et al., 1983; Maslin, 1993]. For the two Deep-Sea Drilling Project (DSDP) cores, both sites are situated close to DSDP sites with high resolution $\delta^{18} \mathrm{O}$ stratigraphies available, which can be accessed by correlation between the sites based on carbonate and/or WCMS records [e.g., Robinson and McCave, 1994]. In this study we have reproduced the $\delta^{18} \mathrm{O}$ data on core 82-PCS-01 from Kidd et al. [1983]. These were obtained by N. J. Shackleton from specimens of the planktonic foraminifera Globigerina bulloides, taken at $10-\mathrm{cm}$ intervals.

\section{Results}

The results of this study fall into three distinct categories. First, we present the magnetic susceptibility records of our cores, with supporting stratigraphic data where relevant, and establish correlations among and between groups of cores taken in regions from within, and to the south and north, of the belt of high IRD input in the NE Atlantic, as defined by Ruddiman [1977a, b]. Second, we examine more closely the basis of the apparent relationship between variations in the MS signal and IRD content of NE Atlantic sediments, using both sedimentological and rock magnetic techniques applied to selected cores. Finally, the paleoceanographic significance of the relationship between IRD and MS in NE Atlantic cores is demonstrated in a time-slice study of variations in the MS of deep-sea sediments in the LGM North Atlantic relative to the present day. The implications of this reconstruction are then considered in the discussion section which follows.

\section{MS Records From South of the Zone of High IRD Input}

The King's Trough Flank area of the NE Atlantic (shaded box in Figure 1) lies some three degrees of latitude south of the maximum southerly extent of the polar front during Pleistocene glaciations. It therefore lies within the zone of light ice-rafted sediment input during glacials identified by Ruddiman and McIntyre [1976, p. 122]. This zone is characterised by noncarbonate sand mass accumulation rates (MAR) of $<100 \mathrm{mg} \mathrm{cm}^{-2} \mathrm{ky}^{-1}$, according to Ruddiman's [1977b] more precise definition of IRD depositional zones in the Pleistocene North Atlantic. Discrete sample MS $(\chi)$ records of eight gravity cores taken from various locations within the King's Trough Flank area (Table 1) have been used to correlate between the cores with 2-cmscale ( $\sim 1 \mathrm{kyr})$ precision, simply by pattern-matching the high-resolution MS profiles (Figure 2). Correlative MS peaks in each core are labelled 1 through 14 in Figure 2, though the intervening MS minima can also be used for correlation purposes. The basis of this correlation is primarily lithostratigraphic, but it is also related to paleoclimatic oscillations, as indicated here by the oxygen isotope stratigraphy of the cores [after Weaver, 1983]. Generally higher MS values characterize glacial intervals of the cores, which represent periods of lower biogenic carbonate (particularly coccolith) productivity in the King's Trough Flank area, and both generally higher levels of ice-rafted sediment input relative to interglacials, as well as distinct episodes of intense ice-rafting activity [Robinson, 1986a]. The King's Trough Flank area lies well above the regional lysocline, throughout glacial and interglacial stages of the Pleistocene [Kidd et al., 1983 p. 13], thus dissolution of carbonate constituents does not complicate further the relationship between climate, lithology, and MS of the sediment in this region.

Robinson [1990, p. 760] suggested that MS peaks within glacial and interglacial horizons of the King's Trough Flank cores (labelled 1 - 14 in Figure 2) appear to correlate with regional ice-rafting episodes as identified by Heinrich [1988], as well as with more widely recognized stadial paleoclimatic events which are manifested not only in IRDrelated parameters, but also in $\delta^{18} \mathrm{O}$ records (i.e., isotopic events $2.2,3.2,4.2,5.2,5.4,6.2,6.4$, etc., as defined by Prell et al. [1986]). Glacial-interglacial variations in MS are largely driven by carbonate dilution and productivity effects on magnetic mineral concentration in the bulk sediment. This, in effect, represents the lithologically-controlled "background" component of variance in the bulk sediment MS signal of the cores. The higher-frequency, stadial-interstadial variations in MS, however, are related to the distinct icerafting pulses, and these may also be associated with changes in the composition and concentration of magnetic minerals within the noncarbonate fraction of the cores [Robinson, 1986a, b]. This suggests differences in the source(s) of background IRD input in glacial horizons, relative to the distinct IRD pulses. Several MS peaks related to ice-rafting episodes can be seen to vary in intensity across the King's Trough Flank area (Figure 2). For example, the MS peak in $\delta^{18} \mathrm{O}$ stage 4 declines in importance from the south of the region (cores S8-79-1 and 2) to the north (core S8-79-8).

Although the whole-core volume-MS $(\kappa)$ records of the King's Trough Flank gravity cores have been described in previous studies [Robinson, 1986a, 1990], the $\chi$ data shown in Figure 2 appear in published form for the first time here. The essential difference between the whole-core $x$ and discrete-sample $\chi$ records of these cores is the higher signalto-noise ratios of the latter, thus revealing more precisely the low-amplitude, yet statistically significant variation in MS within carbonate-rich interglacial intervals of the cores. Such variations appear to covary directly with paleoclimatic oscillations as indicated by the isotopic stratigraphy of the cores (i.e., $\delta^{18} \mathrm{O}$ substages $5 \mathrm{a}$ to $5 \mathrm{e}$ ). Correlation lines in Figure 2 are drawn between isotopic stage boundaries in the cores identified in $\delta^{18} \mathrm{O}$ records from all eight cores, based on measurements made at 5 - or $10-\mathrm{cm}$ intervals [Weaver, 1983], and at 5-cm intervals in two undisturbed piston cores from the same area, which have much higher apparent accumulation rates and correspondingly higher resolution $\delta^{18} \mathrm{O}$ profiles [Kidd et al., 1983]. Isotopic and other stratigraphic data can be extrapolated between any of the King's Trough Flank cores by means of intercorrelation based on their MS records, as shown in Figure 2. This stratigraphic application for MS profiling is also exemplified by the correlation shown in Figure 3, between the wholecore $\kappa$ records of two piston cores from the King's Trough Flank area (uppermost 5 or $6 \mathrm{~m}$ only), illustrating how stratigraphic data from one core (82-PCS-01) may be extrapolated to the other (82-PCS-04) with centimeter-scale precision.

The stratigraphic interval encompassed by the 5- and 6- 




Figure 3. Whole-core, volume magnetic susceptibility $(x)$ profiles of King's Trough Flank piston cores 82-PCS-01 and 82-PCS-04 (2-cm intervals), with supporting calcimetric and $\delta^{18} \mathrm{O}$ data from core 82-PCS-01 (10-cm intervals), and the \%IRD sand record from Heinrich's [1988] core Me69-17 shown for comparison. Numbered features in the $\delta^{18} \mathrm{O}$ record correspond to isotopic events, as defined in the scheme of Prell et al. [1986]. Note the much higher apparent accumulation rate of these piston core records, relative to the King's Trough Flank gravity cores shown in Figure 2. This is merely an artifact of the different methods of coring: the gravity cores being severely foreshortened [Weaver and Schultheiss, 1983].

metre long piston core records in Figure 3 is approximately the same as that sampled by the $\mathbf{2}$ to $\mathbf{2 . 5}$ metre long King's Trough Flank gravity cores. The differences in apparent accumulation rate between the piston and gravity cores are merely an artifact of the different methods of coring, with clay-rich (glacial) intervals of the gravity cores being the most attenuated [Weaver and Schultheiss, 1983]. Because of coring related differences in the apparent accumulation rates of the cores, in Figure 3 and subsequent figures we have varied the depth scales of the downcore records illustrated, such that the stratigraphic intervals of the cores are more or less equivalent. Plotting the data as a function of age would obviously have avoided this problem but would have required us here to explain the bases of the various age models used, complicating unduly the present study, where only one core requires an age model, which is outlined below.
The correlation first suggested by Robinson [1990], between MS peaks in the King's Trough Flank cores and regional ice-rafting events identified by Heinrich [1988] in core Me69-17, and other cores from the Dreizack Seamount region (Figure 1), is shown in Figure 3 (left). The three records from core 82-PCS-01 show that background glacialinterglacial variations in MS, as with the King's Trough Flank gravity cores (Figure 2), are largely controlled by changes in noncarbonate content of the sediment, and these parallel variations in planktonic $\delta^{18} \mathrm{O}$. In the King's Trough Flank area, as noted above, variations in the carbonate content of sediments are controlled largely by an in-phase, reciprocal relationship between changes in biogenic productivity and dilution by terrigenous detritus delivered mainly by ice-rafting. However, variations in MS within glacial horizons are, to a considerable degree, independent of carbonate changes, and appear to covary with the horizons 
of high IRD sand content in Heinrich's core Me69-17. Some of these episodes have been termed "Heinrich events" by Broecker et al. [1992], and they have been referred to as such in subsequent studies [e.g., Bond et al., 1992, 1993; Grousset et al., 1993; MacAyeal, 1993a, b; Alley and MacAyeal, 1994]. In Heinrich's original study, however, twelve such IRD episodes were recognized, eleven of which were numbered (Figure 3), with those episodes numbered 6, 8,10 , and 11 apparently correlating with isotopic events 4.2 , $5.2,5.4$, and 6.2 , respectively. This is important with respect to the MS profiles of the King's Trough Flank cores because it confirms that the MS variations within interglacial horizons which appear to correlate with isotopic events (e.g., the MS peaks in $\delta^{18} \mathrm{O}$ stage 5 which apparently correlate with isotopic events 5.2 and 5.4), actually do represent changes in IRD influx. We suggest that, while Heinrich events 1 - 5 represent quite distinctive, high-frequency IRD pulses (the origins of which are discussed in detail by Broecker et al. [1992]; Bond et al. [1992, 1993], and Grousset et al. [1993]), subsequent Heinrich events (i.e., peaks in Heinrich's cores which the author originally numbered $6-11$ ), and background variations in IRD input between glacial and interglacial horizons, are more directly linked to orbitallyforced, paleoclimatic changes seen also in carbonate and $\delta^{18} O$ curves, and thus may be correlated with (cold) isotopic events (e.g., Figure 3 right).

With regard to the stratigraphy of Heinrich events and their correlative, or otherwise, isotopic events as shown in Figure 3, note that we have reproduced Heinrich's data (including $\delta^{18} \mathrm{O}$ stratigraphy) exactly as in the original article. This shows that the boundary between $\delta^{18} \mathrm{O}$ stages 1 and 2 occurs prior to Heinrich event 1 in core Me69-17. However, subsequent ${ }^{14} \mathrm{C}$ dating of Heinrich events [e.g., Broecker et al., 1992; Bond et al., 1992] have indicated that $\mathrm{H} 1$ occurred around $14.6 \mathrm{ka}\left({ }^{14} \mathrm{C}\right.$ years, or $17.2 \mathrm{ka}$ calendar years), which is earlier than the $\delta^{18} O$ stage $1 / 2$ boundary, put at $12 \mathrm{ka}$ in the SPECMAP chronology of Imbrie et al. [1984]. The planktonic $\delta^{18} \mathrm{O}$ profiles of the King's Trough Flank cores show no significant response to Heinrich events 1 - 5. This may be because of the low resolution of the records, or possibly because the King's Trough Flank area lies too far south to be affected by major iceberg meltwater influx. Further north, at DSDP site 609 (Figure 1), Bond et al. [1992] found that there were distinct $\delta^{18} \mathrm{O}$-light intervals associated with these Heinrich events. More recently, estimates of sea surface salinity at two BOFS sites, $5 \mathrm{~K}$ and $8 \mathrm{~K}$, based on planktonic $\delta^{18} \mathrm{O}$ and foraminiferal assemblages, showed that there were significant influxes of fresh, glacial meltwater at both sites (Figure 1) during each of the last four Heinrich events [Maslin, 1993]. However, Shackleton et al. [1993] found that there were no significant changes in the benthic $\delta^{18} \mathrm{O}$ records of the BOFS cores during Heinrich events $1,2,3$, and 5 . A tentative correlation between $\mathrm{H} 4$ and isotopic event 3.2 may be suggested on the basis that, in the SPECMAP chronology of Imbrie et al. [1984], $\delta^{18} \mathrm{O}$ event 3.2 occurs between $28 \mathrm{ka}$ and $53 \mathrm{ka}$, and ${ }^{14} \mathrm{C}$ dating has placed $\mathrm{H} 4$ at between $38 \mathrm{ka}$ and $41 \mathrm{ka}$ [Broecker et al., 1992; Bond et al., 1992]. However, it is unlikely that Heinrich events $1,2,3$, and 5 correspond to any of the benthic (i.e., global) $\delta^{18} \mathrm{O}$ events related to orbitally forced ice-volume changes, as defined in the scheme of Prell et al. [1986]. In contrast, IRD events H6, 8, 10, and 11 (and 12), as originally defined by Heinrich [1988], clearly do correlate with isotopic events $4.2,5.2$ (though this is poorly defined in the $\delta^{18} \mathrm{O}$ profile of core 82-PCS-01, but can be inferred from its $\% \mathrm{CaCO}_{3}$ record), 5.4, 6.2 (and 6.4), respectively. In all of the cores from the King's Trough Flank area, and in several cores from north of the zone of high IRD imput, $\mathrm{H3}$ is absent or poorly defined in MS records. This may indicate that the source of the IRD associated with $\mathrm{H} 3$ differs to that of the other Heinrich events (as suggested by Bond et al. [1992] and Grousset et al. [1993]) and has a magnetic mineral content similar to that of the backround IRD in glacial horizons, or that $\mathrm{H} 3$ is of limited areal extent, or both.

\section{Correlation With MS Records From Inside the Zone of High IRD Input}

A correlation is proposed in Figure 4 between the wholecore MS $(\kappa)$ profiles of the upper horizons of three of the King's Trough Flank cores, including piston core 82-PCS-04 (as shown in Figure 3), and gravity cores S8-79-2 and S879-5 (not $\chi$, as in Figure 2, but $\kappa$ here), and the \%IRD sand record of the equivalent interval in Heinrich's core Me69-17. The correlation is also extended to encompass the whole-core MS profiles of two further cores from the same region as Heinrich's core, that is, from within Ruddiman's [1977b] zone of high IRD imput during Pleistocene glaciations (noncarbonate sand accumulation rates of $>200 \mathrm{mg} \mathrm{cm}^{-2}$ $\left.\mathrm{kyr}^{-1}\right)$. In fact BOFS core $5 \mathrm{~K}$ was taken in the region of highest IRD sand input during glacials identified by Ruddiman [1977b] (>300 $\left.\mathrm{mg} \mathrm{cm}^{-2} \mathrm{ky}^{-1}\right)$. Our MS records from within the zone of high IRD imput all come from gravity or Kasten box cores, and are therefore rather short (capturing events H1 - H4 only), especially because of the high accumulation rates in this region. It is for this reason that we have reproduced on a larger scale some of the MS data from the King's Trough Flank cores, as well as the \%IRD sand data from core Me69-17, in order to compare with the short, but very high resolution WCMS records from the gravity and Kasten cores.

The $\delta^{18} \mathrm{O}$ stratigraphic framework constraining the WCMS correlations shown in Figure 4 is obtained from individual $\delta^{18} O$ records for cores S8-79-2 and S8-79-5 [Weaver, 1983]; from the $\delta^{18} \mathrm{O}$ record of core 82-PCS-01 extrapolated to core 82-PCS-04 by means of intercorrelation based on their WCMS profiles (Figure 3); and from the $\delta^{18} \mathrm{O}$ record for BOFS core 5K [Maslin, 1993], extrapolated to core D9812 by correlation based on the MS profiles shown here. Further chronostratigraphic control is given by the ${ }^{14} \mathrm{C}$ dates for each of the Heinrich events in BOFS core 5K (B. Manighetti, M.A. Maslin, I.N. McCave, and N.J. Shackleton, Chronology for climate change: Developing age models for the BOFS cores, submitted to Paleoceanography, 1994, hereinafter referred to as Manighetti et al., submitted manuscript, 1994). The very high resolution WCMS record of this core enabled the precise identification of the acme of each Heinrich Event, and these were the horizons sampled for ${ }^{14} \mathrm{C}$ dating. The subsequent ages obtained for each horizon sampled proved to be within $1 \mathrm{kyr}$ of the ${ }^{14} \mathrm{C}$ dates obtained 


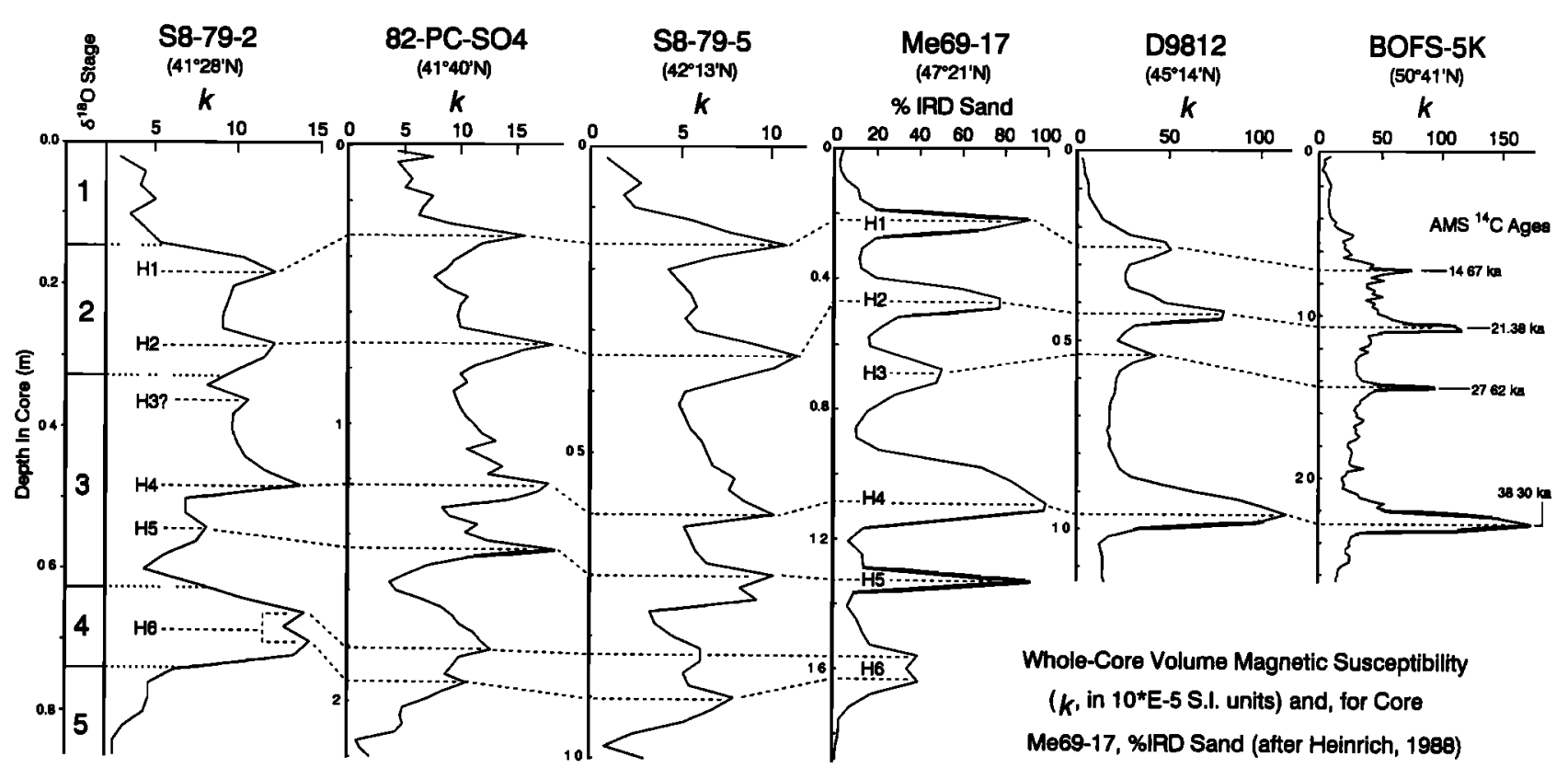

Figure 4. Correlation between gravity and piston cores from the King's Trough Flank area, which lies south of the polar front during Pleistocene glacials (a zone of "light" IRD input according to Ruddiman and McIntyre [1976]), and Kasten box-cores D9812 and BOFS-5K from north of the glacial polar front (a zone of "heavy" IRD imput), based on matching whole-core volume MS ( $\kappa$ ) profiles of each core (2-cm interval data). The possible correlation between these regional variations in the MS profiles of deep-sea cores and the Heinrich IRD events is also indicated with reference to the \% IRD sand record of Dreizack Seamount core Me69-17 [after Heinrich, 1988]. The figure also shows the ${ }^{14} \mathrm{C}$ dates for these IRD events in BOFS core 5K (after Manighetti et al., submitted manuscript, 1994).

by Broecker et al. [1992] for Heinrich events 1 - 4 in DSDP 609. This provides independent confirmation that the MS signal of BOFS core $5 \mathrm{~K}$ is directly related to these IRD events.

The absolute intensity of IRD events all increase markedly between the King's Trough Flank area and the zone of high IRD input, as reflected in the much higher $\kappa$ values for these events in cores D9812 and BOFS-5K. However, the relative intensity of IRD events varies with latitude. For example, IRD events $\mathrm{H} 1$ and $\mathrm{H} 6$ appear to diminish in relative importance, whereas events $\mathrm{H} 2, \mathrm{H} 3, \mathrm{H} 4$, and $\mathrm{H} 5$ all appear to become relatively more intense between the south and north of the King's Trough Flank area, and between the King's Trough Flank and the east Thulean Rise (BOFS 5K).

Correlation Among MS Records From Inside and to the North of the Zone of High IRD Input

The WCMS $(\kappa)$ profiles of further BOFS Kasten cores, together with piston cores from two intermediate DSDP sites (Figure 5), enable us to extend the MS-based correlation still further north from BOFS station 5K, within Ruddiman's [1977b] zone of highest IRD sand imput during glacials ( $>300 \mathrm{mg} \mathrm{cm}^{-2} \mathrm{ky}^{-1}$ ), through BOFS-8K and DSDP site 610 , both in the zone of high glacial IRD sand input (200 - 300 $\mathrm{mg} \mathrm{cm} \mathrm{ky}^{-1}$ ), to BOFS cores $17 \mathrm{~K}$ and $14 \mathrm{~K}$, north of the zone of high IRD imput, lying in Ruddiman and McIntyre's [1976] zone of moderate IRD sand input $\left(100-200 \mathrm{mg} \mathrm{cm}^{-2}\right.$ $\left.\mathbf{k y}^{-1}\right)$. It is clear from the differences in WCMS values associated with IRD events in these cores that the intensity of IRD deposition varies significantly between each zone. Most notably, DSDP 610 lies marginally within the zone of high glacial IRD imput, whereas DSDP 553, taken from the opposite flank of the Rockall Plateau (Figure 1), lies within the zone of moderate IRD input. Consequently, in DSDP 553 , and in the other cores from north of the high-IRD zone, it is difficult to identify individual Heinrich events, or to distinguish between $\mathrm{H} 1, \mathrm{H} 2$ and the more ubiquitous LGM culmination in background IRD deposition upon which the high-frequency Heinrich IRD pulses are superimposed. It is important to note in this context, however, that all of the BOFS cores have very high resolution $\delta^{18} \mathrm{O}$ profiles available to constrain WCMS correlations [Maslin, 1993]. Similarly, for DSDP site 553, this lies very close to site 552, and we have been able to correlate between the two sites using WCMS profiles from each site (WCMS data from site $\mathbf{5 5 2}$ supplied by John King and coworkers from the University of Rhode Island). This allows us to extrapolate the $\delta^{18} \mathrm{O}$ stratigraphy for site 552 [Shackleton and Hall, 1984] to site 553. For site 610, we have correlated between WCMS profiles from this site and from site 609 [e.g., Robinson and McCave, 1994], thus accessing the composite $\delta^{18} \mathrm{O}$ stratigraphy developed for site 607 by Ruddiman et al. [1989], which the authors themselves extrapolated to site 609 by means of correlating between carbonate content records from each site. Therefore, for all of the cores shown in Figure 5, although it becomes increasingly difficult to 


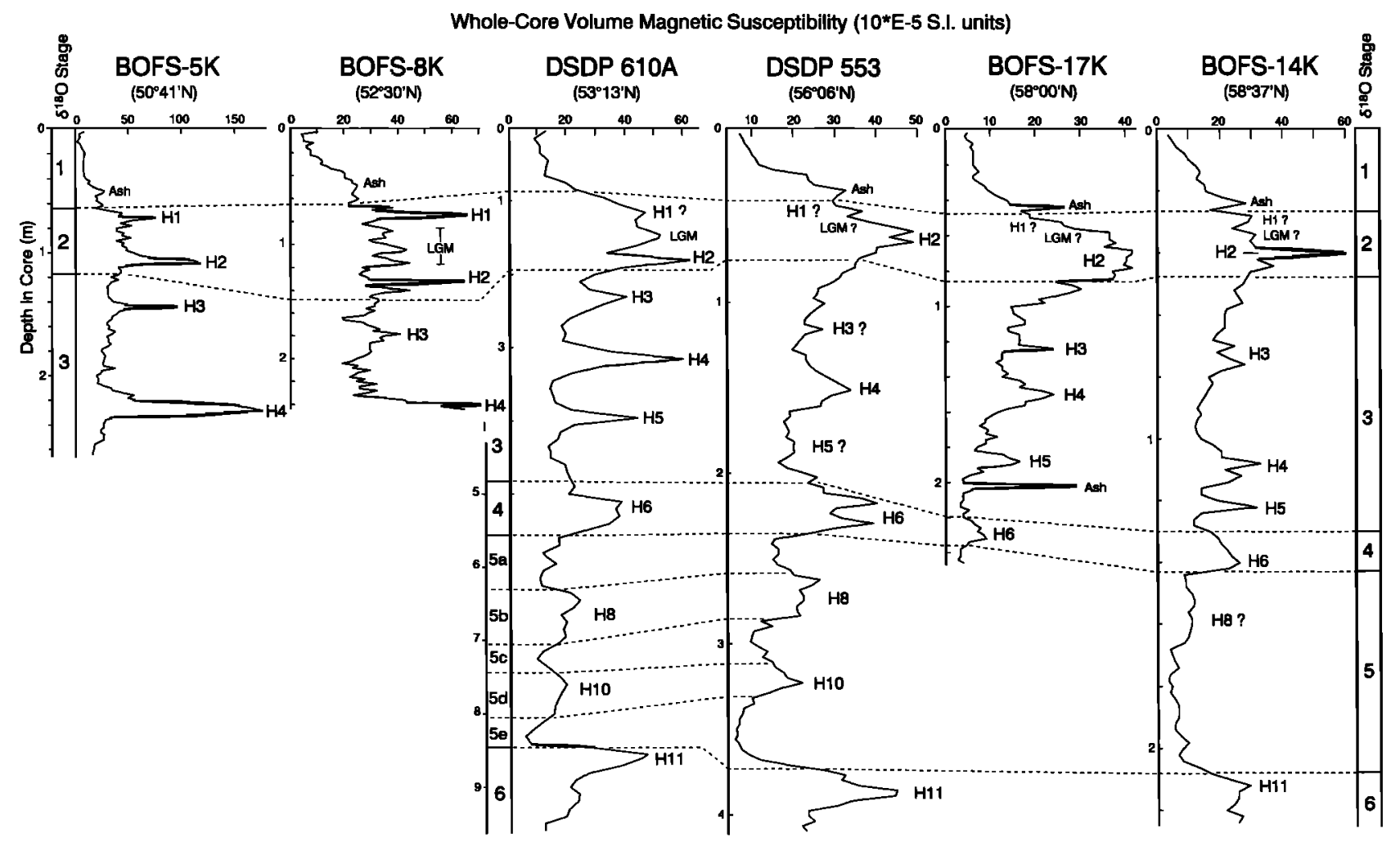

Figure 5. Whole-core MS ( $\kappa$ )-based correlation of BOFS Kasten cores and DSDP hydraulic piston core 610A-1H, all from within Ruddiman and McIntyre's [1976] zone of "heavy" IRD imput during Pleistocene glacials, with cores from north of this zone, including DSDP cores from site 553, and BOFS cores $17 \mathrm{~K}$ and $14 \mathrm{~K}$, which are from a region of "moderate" IRD input during glacials. Correlation lines connect $\delta^{18} \mathrm{O}$ stage or substage boundaries identified as described in the accompanying text. The additional correlative features in these profiles suggested here relate to regional IRD events, H1 - H11 (as originally identified by Heinrich [1988]), which are clearly not well-represented in cores from north of the zone of heavy IRD input.

distinguish between Heinrich or other IRD events in cores from outside of the zone of high IRD imput, the suggested correlations between WCMS peaks and IRD events are at. least constrained to within a rigorous $\delta^{18} \mathrm{O}$ framework.

For cores from DSDP sites 610 and 553, as in the case of the King's Trough Flank cores, it is possible to identify variations in WCMS within interglacial $\delta^{18} \mathrm{O}$ stage 5 which correspond, in all probability, to isotopic events 5.1 - 5.5. We can therefore identify WCMS peaks relating to all eleven of the original North Atlantic IRD events identified by Heinrich [1988] in Dreizack Seamount cores (e.g., Me69-17, Figure 3), and thus correlate, in detail, between cores from $40^{\circ}$ to $56^{\circ} \mathrm{N}$. For individual IRD events, we can correlate between all of the cores shown in Figures 2 - 5, thus allowing us to compare variations in MS as a function of latitude (along a line of transect centred on or around $20^{\circ} \mathrm{W}$ ) for different ice-rafting episodes (Figure 6).

The variation in glacial/Holocene MS ratios between $41.5^{\circ}$ and $58.5^{\circ} \mathrm{N}$ (at longitude $20^{\circ} \mathrm{W}$ ), for five ice-rafting episodes identified in eleven of the cores shown in Figures 2 - 5 (plus core BOFS-3K, not shown), are plotted in Figure 6. Clearly, variations in MS parallel closely trends in IRD deposition in this region, at least during the last four
Heinrich events, and for the LGM between $\mathrm{H} 1$ and $\mathrm{H} 2$. The transects confirm our earlier observations that different IRD events vary in intensity, both in relative and absolute terms, across the region. The strongly pronounced drop in glacial/Holocene MS ratios marking the position of the boundary between the zones of high and moderate IRD sand input during glacials $\left(\sim 200 \mathrm{mg} \mathrm{cm}^{-2} \mathrm{ky}^{-1}\right)$ is particularly noticeable in the case of the four Heinrich events. So strong is this contrast, in fact, that Grousset et al. [1993] described the zone of high MS values in the NE Atlantic as "the IRD belt". It must be stressed, however, that the MS signal of NE Atlantic sediments in areas beyond this belt is still controlled largely by variations in IRD input, though oscillations are lower, both in amplitude and frequency, and are more directly controlled by carbonate dilution and productivity cycles. Thus Figure 6 confirms that the IRD depositional zones delineated by Ruddiman and McIntyre [1976], and more precisely by Ruddiman [1977a, b], correspond to regions where the MS of sediments deposited reflect directly the amount of IRD they contain. This suggests that we could reconstruct patterns of IRD deposition in the NE Atlantic based on mapping variations in MS-ratios for glacial/interglacial time slices (cf. CLIMAP project). 
IRD Sand Input at $20^{\circ} \mathrm{W}$ During Glacial Maxima $\left(\mathrm{mg} / \mathrm{cm}^{2} / \mathrm{kyr}\right)$



Figure 6. Transects snowing the variation in $\mathrm{MS}_{\text {Glacial }}$ MS $_{\text {Holocene }}$ ratios as a function of latitude in the NE Atlantic, between $40^{\circ}$ and $60^{\circ} \mathrm{N}$ (along longitude $20^{\circ} \mathrm{W}$ ), for five late Pleistocene ice-rafting episodes: Heinrich events $1-4$, and the LGM ( 18-19 ka). The vertical axis plots the MS value for a given IRD event in each core, divided by the MS value for the Holocene minimum (climatic optimum) in the same core. The horizontal axis plots latitude, with the positions of the various coring stations indicated, and also the zones of ice-rafted noncarbonate sand input (at $20^{\circ} \mathrm{W}$ ) mapped by Ruddiman [1977b].

Before attempting such a reconstruction, however, we must first establish that there is a rational basis, both sedimentological and rock-magnetic, for using the MS signal of NE Atlantic deep-sea sediments as a proxy for their IRD content.
Sedimentological Evidence for a Direct Link Between the MS and IRD Content of NE Atlantic Sediments

Here we present sedimentological data from two BOFS cores which are of the same kind as those used to identify IRD events in Heinrich's study, and compare these data with the MS records of the BOFS cores. Such comparisons, however, can only reveal a covariance between the MS signal and IRD content of the cores, they do not constitute evidence for a direct, causal relationship. The possibility that such a linkage exists is examined in the next section.

A comparison between the WCMS ( $\alpha$ ) profiles of BOFS cores $5 \mathrm{~K}$ and $8 \mathrm{~K}$ and their records of coarse fraction (>150 $\mu \mathrm{m})$ lithic fragment (IRD sand) and $N$. pachyderma (sin) abundances (Figure 7) shows that variations in the background level of MS are clearly paralleled by similar shifts in each of the other two parameters. Additionally, distinct peaks in MS clearly correspond to major episodes of IRD sand influx and to significant increases in the abundance of $N$. pachyderma (sin), where this species does not already dominate the planktonic foraminiferal assemblage in the core. Therefore, the suggested correlation between Heinrich events and peaks in the MS records of these cores (and other cores shown in previous figures) is here confirmed by the \%IRD sand profiles of the cores. These profiles may be correlated directly with Heinrich's data of the same kind from core Me69-17 (Figure 4), noting that, in all cases, detailed $\delta^{18} \mathrm{O}$ stratigraphies are available to constrain the lithostratigraphic correlations.

Foraminiferal dissolution effects are minimal for most of the record in BOFS cores $5 \mathrm{~K}$ and $8 \mathrm{~K}$, so variations in the abundance of lithic fragments in coarse fractions are controlled mainly by IRD influx and, during Heinrich events, lower foraminiferal productivity, as noted by Broecker et al. [1992]. The only exception in this regard is $H 3$, which has been shown previously to exhibit significantly higher foraminiferal fragmentation than any other interval during the last glacial period [Simet et al., 1992]. This again indicates the comparative uniqueness of the H3 IRD event.

There are a number of peaks in the \% IRD sand profiles of cores $5 \mathrm{~K}$ and $8 \mathrm{~K}$ (Figure 7) which are not paralleled by similar features in the MS profiles of the cores, especially prior to, and associated with, $\mathrm{H} 3$. This suggests that periods of enhanced ice-rafting activity are associated with multiple episodes of IRD influx, and that some are characterized by deposition of coarse fraction lithic material of low magnetizable mineral content (i.e., containing a lot of quartz, alkali feldspar, or indeed the carbonate rock fragments which Bond et al. [1992] noted as being important components in Heinrich events $1,2,4$, and 5). In core BOFS-5K, H3 is represented by only one MS peak which is relatively small compared with the large, multiple peaks associated with this event in the \%IRD sand record of the core. In BOFS-8K, and in cores from north of the zone of high IRD input (Figure 5), H3 is characterized by only a very weak MS signal, and any features attributable to this IRD event appear to be absent from the MS records of all cores from the King's Trough Flank area (south of the glacial polar front). Significant differences in the MS signal of individual IRD events may indicate that the detritus deposited is derived from different source regions. 
(a) BOFS-5K

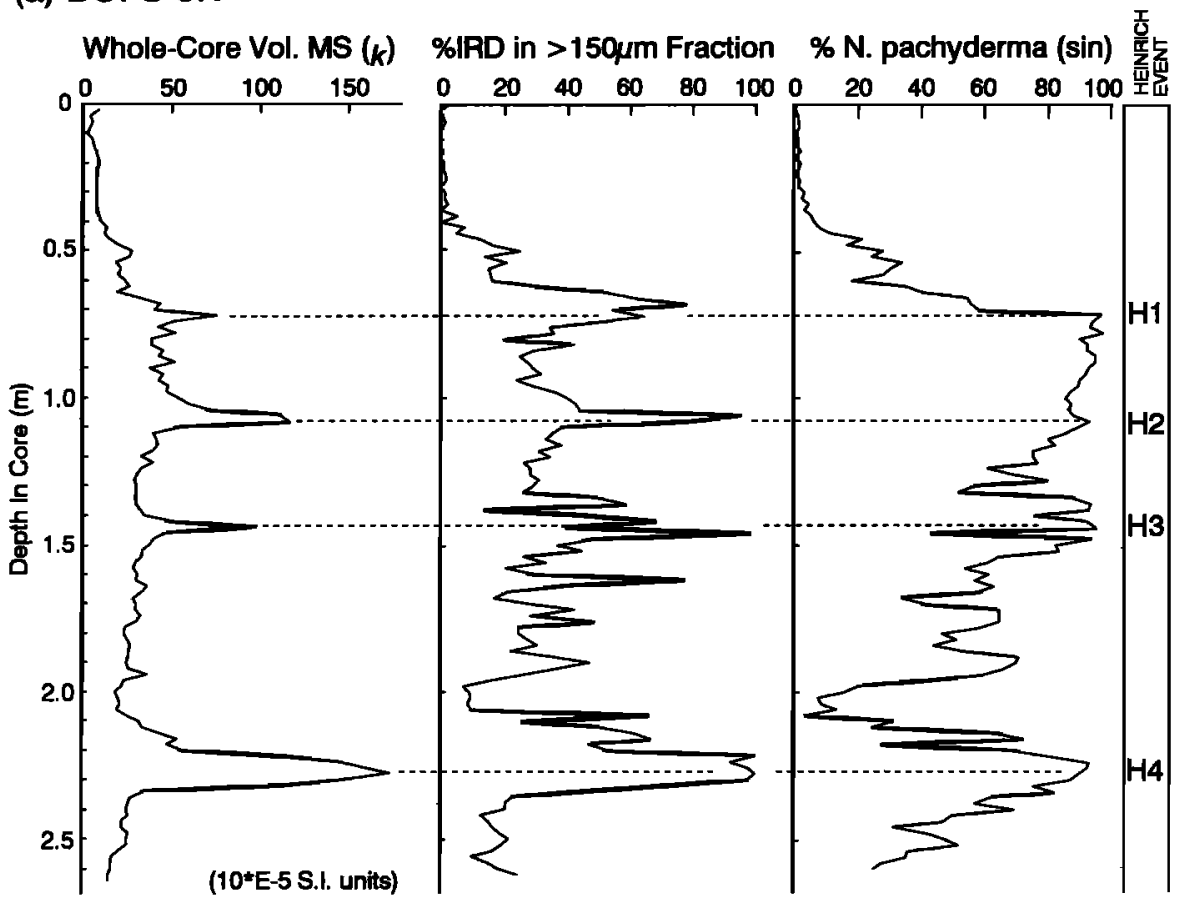

(b) BOFS-8K

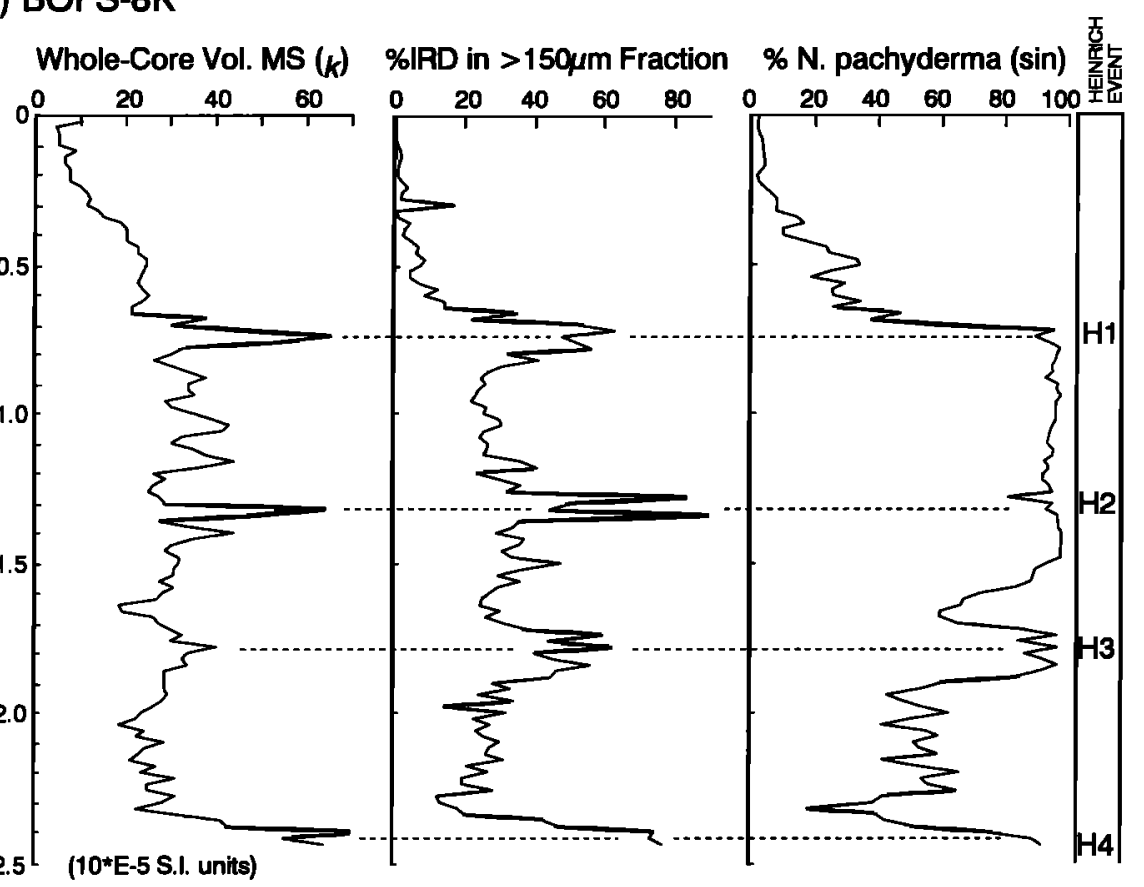

Figure 7. Relationships between whole-core MS ( $\alpha$ ); lithic fragment abundance in $>150-\mu \mathrm{m}$ fractions; and the percentage of left coiling $N$. pachyderma relative to the total number of planktonic foraminifera in $>150-\mu \mathrm{m}$ fractions; for BOFS cores (a) $5 \mathrm{~K}$ and (b) $8 \mathrm{~K}$, both taken from within Ruddiman and McIntyre's [1976] zone of "heavy" IRD imput during glacials. H1 - H4 correspond to Heinrich IRD events 1 to 4.

Rock Magnetic Evidence for a Sedimentological Linkage Between MS and IRD Profiles of NE Atlantic Sediments

The sedimentological data above (Figure 7) demonstrates the empirical basis for using MS as a proxy for monitoring
IRD variations in NE Atlantic sediments. In this section we explore the possibility that there may be a causal link between variations in the IRD content and MS signal of NE Atlantic sediments. We begin by comparing the discrete sample MS $(\chi)$ record from King's Trough Flank core S8- 
79-4 (as shown in Figure 2) with the carbonate content profile of this core; its $\delta^{18} \mathrm{O}$ and foraminiferal-based climatic stratigraphies [after Weaver, 1983; Kidd et al., 1983]; and its records of variation in the magnetic parameter anhysteretic remanent magnetization, ARM (expressed as anhysteretic susceptibility, $\chi_{\text {ARM }}$ ), and the quotient of MS to ARM (expressed as $\chi / \chi_{\text {ARM }}$ ).

As we noted earlier, for assemblages of magnetic mineral particles in sediments which are larger than the threshold size for superparamagnetic (SPM) behavior ( $\sim 0.03 \mu \mathrm{m}$ for magnetite, or $0.08 \mu \mathrm{m}$ for titanomagnetite [Dunlop, 1981]), ARM and MS covary inversely as a function of grain size [Dankers, 1978; Maher, 1988]. The quotient of MS/ARM thus varies according to trends in the grain size of ferrimagnetic particles within the magnetic mineral fractions of sediments [Banerjee et al., 1981; King et al., 1982; Hall et al., 1989a; Bloemendal et al., 1989, 1992, 1993]. Peaks in MS/ARM indicate the presence of a higher proportion of coarse grained ferrimagnetic particles in magnetic assemblages relative to horizons with lower MS/ARM values, and vice versa. The quotient is independent of carbonate dilution. effects on magnetic concentration, unlike bulk MS and ARM individually. However, whilst ARM is unaffected by the presence of viscous SPM particles in magnetic assemblages, MS is highly sensitive to such components, thus complicating the interpretation of MS to ARM quotients [King et al., 1982]. In the case of core S8-79-4, Robinson [1986a] showed that variations in both the ARM/SIRM and ARM/MS quotients downcore are virtually identical, thus indicating that viscous-SPM components constitute an insignificant contribution to the MS signal of this core.

For core S8-79-4, variations in $\mathrm{CaCO}_{3}$ content, $\mathrm{MS}$ and ARM are all clearly modulated by paleoclimatic influences (Figure 8). A considerable proportion of the variance in both the MS and ARM signals of this core must be related to variations in carbonate content of the sediment, which dilute or concentrate the lithogenic fraction where most of the magnetic mineral assemblage is located. However, unlike the MS profile of the core, the ARM record (and, to a lesser extent, the $\% \mathrm{CaCO}_{3}$ profile) does not exhibit a series of

\section{Core: $\$ 8-79-4$}

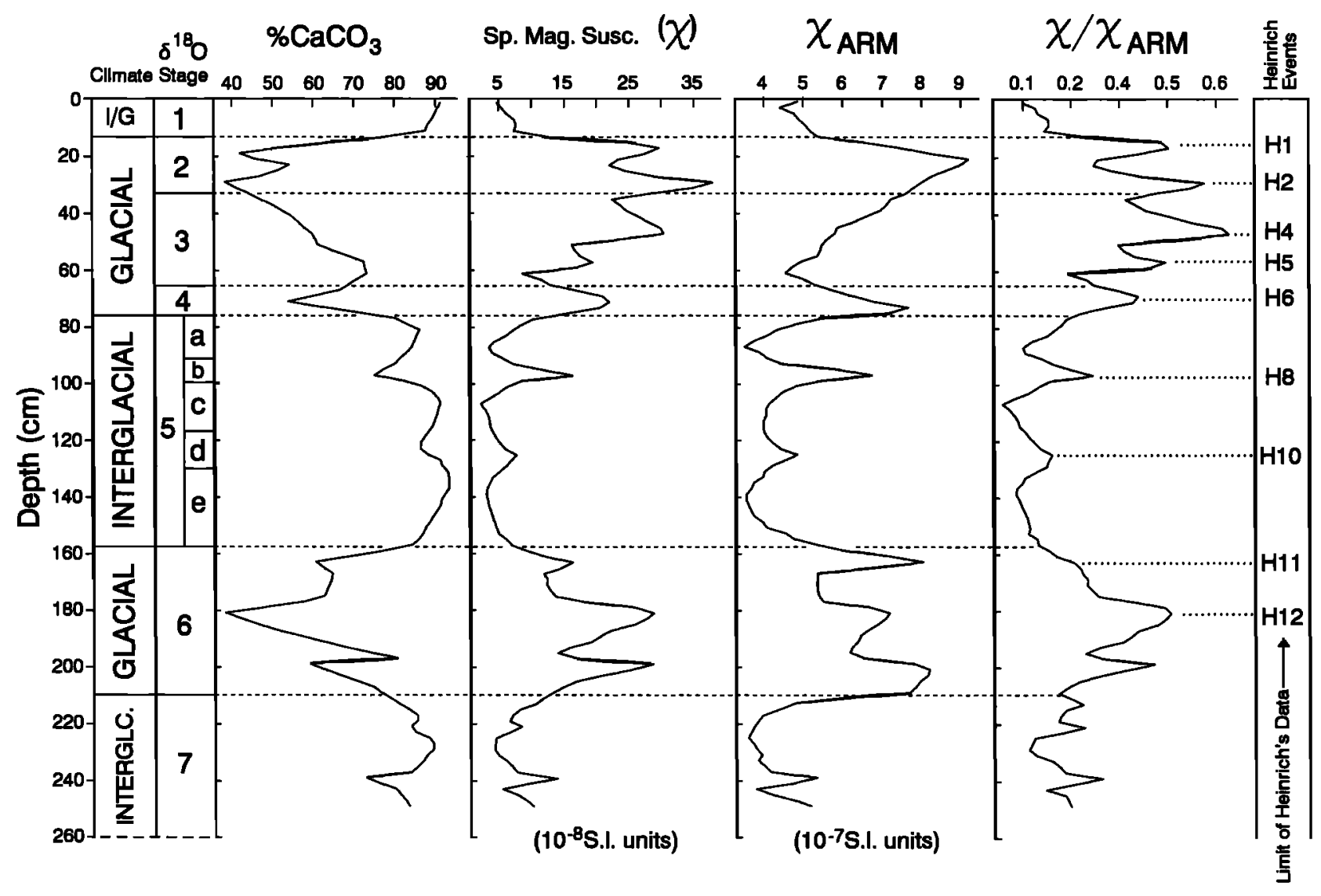

Figure 8. Covariation of carbonate content and rock magnetic properties of King's Trough Flank gravity core S8-79-4: paleoclimatic significance and relationship to Heinrich IRD events. The rock-magnetic properties MS $(\chi)$ and ARM $\left(\chi_{\text {ARM }}\right)$ are both primarily dependent on magnetic mineral concentration in the sediment which is largely controlled by the proportion of carbonate to noncarbonate components. The quotient MS/ARM $\left(\alpha / \chi_{\text {ARM }}\right)$, however, is independent of carbonate dilution effects and reflects variations in the grain size of magnetic minerals in the sediment: MS/ARM peaks indicate horizons with a high proportion of large ( $>15 \mu \mathrm{m})$, multidomain ferrimagnetic grains. 
subordinate peaks within glacial horizons which, as we have already established, correlate with regional ice-rafting episodes (Heinrich events). Hence the MS peaks which correlate with Heinrich events must be characterized by a magnetic assemblage unusually rich in coarse grained, MD ferrimagnetic grains. This is confirmed by the plot of MS/ARM $\left(\alpha / \chi_{\text {ARM }}\right)$, which is essentially independent of carbonate dilution effects, and shows a very similar downcore pattern of variations to that of the MS profile of the core. Particularly clear are the MS/ARM peaks in response to the Heinrich events in $\delta^{18} \mathrm{O}$ stages $2-4$, and to IRD episodes which correlate with more widely recognized (cold) isotopic events in $\delta^{18} \mathrm{O}$ stages 4,5 , and 6. These events, however, can also be recognized in both the $\% \mathrm{CaCO}_{3}$ and ARM records of the core. Note, for example, how ARM values for the last glacial interval peak at exactly the LGM position in $\delta^{18} \mathrm{O}$ stage 2 , whereas the MS profile shows two distinct peaks in this stage: one before and one after the LGM event, corresponding to Heinrich events $\mathrm{H} 2$ and $\mathrm{H} 1$, respectively.

It is clear from these data that MS variations of core S879-4 are partly driven by carbonate dilution/productivity effects (which largely control variations in the bulk-sediment ARM profile) but that a significant source of variation in the MS profile is related to changes in the grain size of magnetic minerals within the noncarbonate fraction of the sediment. Such variations are directly attributable to the presence in these horizons of significant quantities of IRD which contains a high proportion of terrigenous sand. Thus, in this instance, there exists a sympathetic relationship between variations in sediment particle size and magnetic mineral grain size. Hall et al. [1989a] reported similar findings from a study of ARM/MS and sediment particle size variations at ODP site 645 (Baffin Bay). One explanation for this is simply that large magnetic particles are more likely to occur in sand-sized (or coarser) lithogenic material than in silt or clay grade detritus. Bloemendal et al. [1992] noted that deep-sea sediments from high latitudes, where ice-rafting is the main mechanism for terrigenous sediment supply, have significantly coarser ferrimagnetic grain size assemblages than most other pelagic sediments. In most pelagic regions, ice-rafting is the only mechanism capable of transporting sand-sized terrigenous detritus to the site of deposition, although most of the IRD deposited in the North Atlantic is of $<63 \mu \mathrm{m}$ size [Molnia, 1983]. Only ice-rafting, however, has the potential for transporting large, multidomain (MD) ferrimagnetic grains either as components of polycrystalline lithic fragments, or as discrete, silt-sized particles (which have effective hydraulic diameters of sand grains due to their high specific gravity), and then depositing such grains in mid ocean areas like the King's Trough Flank, directly in response to climatic changes.

An alternative method of normalising the effects of carbonate dilution on bulk-sediment MS and ARM variations, is to simply express these on a carbonate-free basis (Figure 9). In order to assess the effects of expressing the data from core S8-79-4 in this way we can compare the carbonate-free MS and ARM profiles of this core with its bulk sediment MS and ARM data (exactly as in the previous figure) plotted on the same scale for comparison (Figure 9, which also and shows the $\mathrm{CaCO}_{3}$ content profile of the core). The effect of eliminating the variance in bulk-sediment MS due to changes in carbonate content of the sediment produces a profile with no obvious glacial-interglacial signature, but enhances the peaks associated with the stadialinterstadial variations in IRD input. This indicates that these IRD-related peaks are characterized either by changes in the concentration of magnetic minerals within the noncarbonate fraction of the sediment, or by changes in the grain size of ferrimagnetic particles (as has been established already in Figure 8), or both. Peaks in the carbonate-free MS (MS ${ }_{\mathrm{CFB}}$ ) profile mostly correspond to IRD episodes, even those within stage 5 , which confirms the IRD event stratigraphy of Heinrich [1988], who identified several IRD episodes in $\delta^{18} \mathrm{O}$ stage 5 of his cores from the Dreizack Seamount area (e.g., Figure 3 ). The only peaks in the $\mathbf{M S}_{\mathrm{CPB}}$ profile which may not be related to IRD input are associated with horizons rich in volcanic ash, though the uppermost peak in the profile corresponds to North Atlantic Ash Zone 1 of Ruddiman and Glover [1972], which is of ice-rafted origin [Ruddiman and McIntyre, 1981]. However, the volcanic ash associated with the lowermost $\mathrm{MS}_{\mathrm{CFB}}$ peak in $\delta^{18} \mathrm{O}$ stage 6 may be of local pyroclastic origin (Azores), though it serves only to enhance a peak in MS which is at least partly related to the presence of IRD in the sediment (see $\% \mathrm{CaCO}_{3}$ profile).

When plotted on a scale which illustrates clearly downcore trends in carbonate-free ARM $\left(\chi_{\text {ARM }}\right)$, variations in bulk-sediment ARM (as plotted on an amplified scale in Figure 8) appear insignificant by comparison. Clearly, changes in carbonate content of the sediment have the effect of dampening-down, or even masking completely, amplitude variations in ARM resulting from changes in the concentration of fine grained ferrimagnetic components in the sediment. This is why the response of carbonate-free ARM $\left(\mathrm{ARM}_{\mathrm{CFB}}\right)$ to climatic forcing opposes that of bulk-sediment ARM (note the antiparallelism of the two profiles in Figure 9, center). Unlike $\mathrm{MS}_{\mathrm{CFB}}$, the $\mathrm{ARM}_{\mathrm{CPB}}$ profile shows a strong glacial-interglacial signature, with relatively low, invariable values in glacial horizons of the core, and higher, more climatically sensitive values in interglacial stages. Three distinct peaks in $\mathrm{ARM}_{\mathrm{CFB}}$ occur $\delta^{18} \mathrm{O}$ stage 5, each in the warm substages. This indicates that warm interglacial stages of the core are always associated with a relatively high proportion of fine grained (probably single domain) ferrimagnetic particles in the sediment, whether or not they also contain a significant concentration of coarse (multidomain) ferrimagnetic grains (indicated by the $\mathrm{MS}_{\mathrm{CPB}}$ profile). It is very important here to distinguish between the peaks in $\mathrm{ARM}_{\mathrm{CPB}}$ in interglacial $\delta^{18} \mathrm{O}$ stage 5 , and the peaks in $\mathrm{MS}_{\mathrm{CFB}}$ in the same interval. These features are not correlative. For example, the largest peak in the ARM ${ }_{\mathrm{CPB}}$ profile occurs late in substage $5 e$, whereas the large $\mathrm{MS}_{\mathrm{CFB}}$ peak in stage 5 (correlating with IRD event H10) occurs in substage 5d. Thus the ARM peaks occur in (warm) substages $5 \mathrm{a}, 5 \mathrm{~b}$, and $5 \mathrm{e}$, whereas the MS peaks occur in (cool) substages $5 b$ and $5 d$.

The $\mathrm{ARM}_{\mathrm{CFB}}$ and $\mathrm{MS}_{\mathrm{CPB}}$ records of core S8-79-4 appear to be out-of-phase within $\delta^{18} \mathrm{O}$ stage 5 , and totally unrelated elsewhere in the core, because each parameter is sensing different grain size fractions of the ferrimagnetic assemblage 


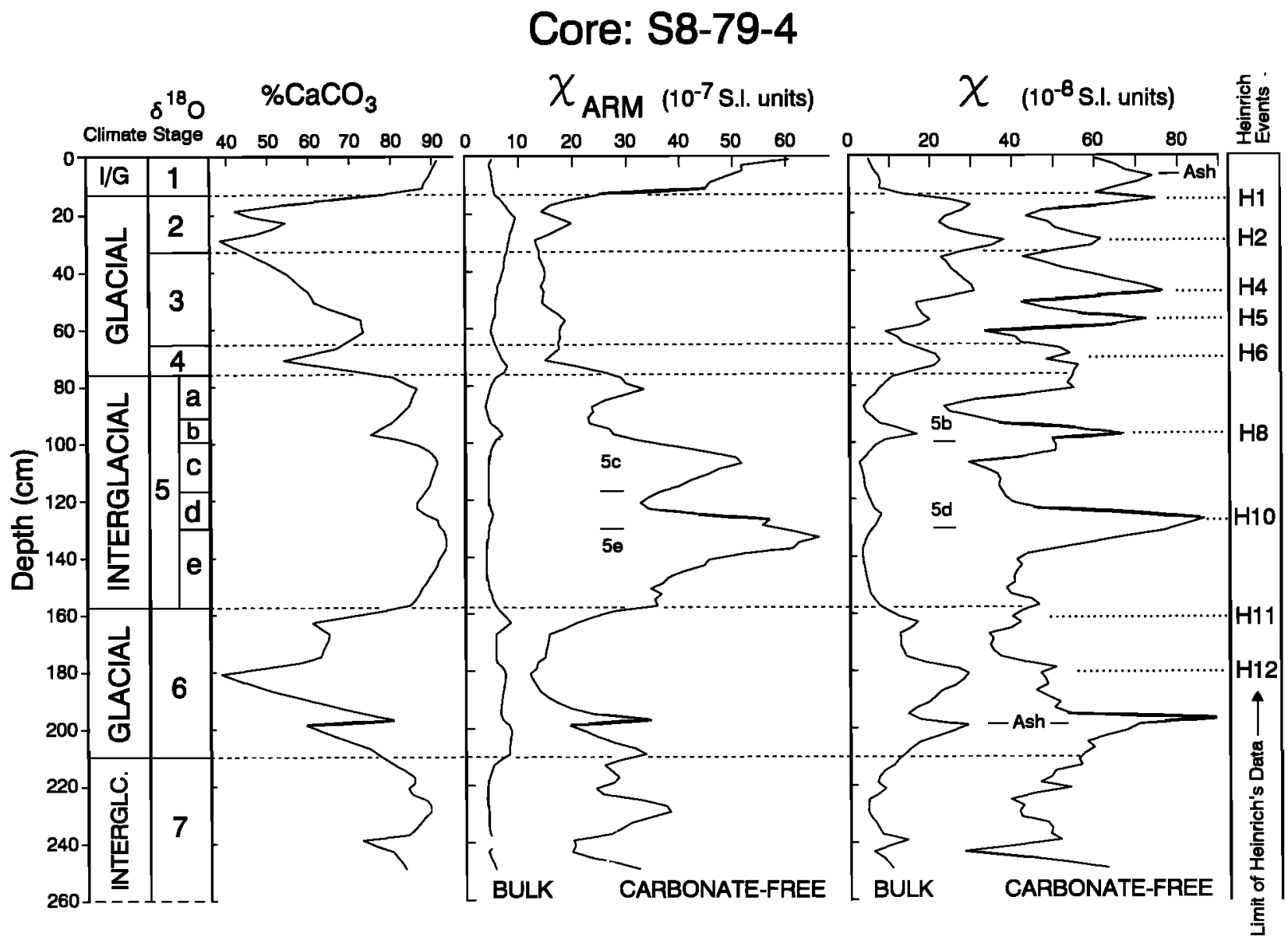

Figure 9. Relationships between carbonate content, bulk MS $(\chi)$ and ARM $\left(\chi_{\text {ARM }}\right)$, and carbonate-free MS and ARM for King's Trough Flank core S8-79-4. The effects of carbonate dilution on bulk MS and ARM can be normalized by expressing these properties on a carbonate-free basis (MS or ARM value divided by the difference between 100 and the $\% \mathrm{CaCO}_{3}$ content of the sample, multiplied by 100 ).

within the sediment. Each size fraction is a genetically distinct magnetic component, varying in concentration within the sediment quite independently, but both in response to climatic forcing. The origin of the fine grained ferrimagnetic component to which $\mathrm{ARM}_{\mathrm{CPB}}$ relates, though obviously interesting from a paleoenvironmental point of view, is not of concern in this study. Robinson [1986a, b] speculated as to its possible bacterial origins, and presented Mössbauereffect spectroscopic data to show that its mineralogy is quite different from that of the coarse grained ferrimagnetic component which dominates the magnetic assemblage of glacial horizons rich in IRD. The origin of the coarse grained ferrimagnetic component to which $\mathrm{MS}_{\mathrm{CPB}}$ relates is clearly IRD, as several lines of evidence have already indicated. However, part of the climatic control of $\% \mathrm{CaCO}_{3}$ variations in this core is also due to dilution by IRD. Hence, by expressing MS on a carbonate-free basis, we are eliminating an important component of variance in the MS record which is associated with "background" IRD input. This background component of variance is the glacial-interglacial change in the rates of biogenic productivity and IRD deposition, upon which the higher frequency Heinrich IRD pulses are superimposed. Thus the $\mathbf{M S}_{\mathrm{CPB}}$ profile elucidates Heinrich events in this core at the expense of other, lowfrequency variations in IRD input. This again suggests that the IRD associated with Heinrich events in this core is derived from a different source to that of the background IRD which is mainly responsible for effecting carbonate dilution cycles at this site. This is consistent with the findings of Broecker et al. [1992] and Bond et al. [1992], based on mineralogical and radioisotopic studies of cores from DSDP site 609 and from the Dreizack Seamount area.

\section{Rock-Magnetic Basis for a MS-IRD Linkage Inside the Zone of High IRD Input}

The whole-core MS profile of core D9812 parallels closely that of core BOFS-5K (Figure 4), which also covaries with coarse fraction lithic fragment abundance and $N$. pachyderma percentage variations in the same core (Figure 7). This shows that the Heinrich events indicated in the normalized rock magnetic records of core D9812 (Figure 10) correlate with horizons in core BOFS-5K which show the same sedimentological characteristics as the IRD events in Heinrich's [1988] original cores (e.g., Me69-17, Figure 
4). Both cores D9812 and BOFS-5K come from within the zone of high IRD input, as defined by Ruddiman [1977b].

In the case of core D9812 (Figure 10), essentially the same relationships can be seen to exist between bulk sediment MS $(\chi)$, MS/ARM $\left(\chi / \chi_{\text {ARM }}\right)$, and MS expressed on a carbonate-free basis $\left(\mathrm{MS}_{\mathrm{CFB}}\right.$, note the change in scale between the plots of bulk sediment $\mathrm{MS}$ and $\mathrm{MS}_{\mathrm{CPB}}$ ) as were shown to exist above (Figures 8 and 9) for core S8-79-4. Bulk sediment MS is strongly influenced by ferrimagnetic grain size variations which are independent of changes in carbonate content of the sediment. In this core even bulk MS can be seen to be partly independent of variations in $\mathrm{CaCO}_{3}$ content. This is because there are significant changes in magnetic concentration within the noncarbonate fraction of the sediment which parallel trends in ferrimagnetic grain size. Hence the bulk MS, MS/ARM, and MS CFB $_{\text {profiles of }}$ this core all covary more or less sympathetically. Peaks in bulk MS related to Heinrich events $\mathrm{H} 1, \mathrm{H} 2$, and $\mathrm{H} 4$ (but not $\mathrm{H} 3$ ) are associated with increases in the concentration and relative proportion of coarse grained, MD ferrimagnetic particles in magnetic mineral assemblages within the noncarbonate fraction of the sediment. This again suggests that the Heinrich IRD events are derived from a different source to that of the background IRD in glacial horizons. The H3 event in this core is more clearly associated with a distinct carbonate low than with a significant peak in any of the magnetic parameters. Since, at this point in the core, there occurs a distinct dropstone layer, we suggest that the $\mathrm{H} 3$ event in this core is not simply an artifact of lower carbonate productivity but is characterized by IRD of lower ferrimagnetic mineral content than $\mathrm{H} 1, \mathrm{H} 2$ and $\mathrm{H} 4$. This suggests again that $\mathrm{H} 3$ derives from a different source region to the other Heinrich events [cf. Broecker et al., 1992; Bond et al., 1992; Grousset et al., 1993], and possibly from the same source region(s) as the background IRD in glacial horizons.

\section{Spectral Characteristics of the Magnetic Records of Core S8-79-4}

The orbital influences on the IRD-related rock magnetic properties of core S8-79-4 can be analysed by spectral analysis of its MS, MS/ARM, and $\mathrm{MS}_{\mathrm{CPB}}$ records (Figures 8 and 9). Variance in the bulk sediment MS signal of this core are partly controlled by changes in carbonate content of the sediment, and partly by changes in the composition of magnetic mineral assemblages within its noncarbonate fraction. In order to deconvolve each of these elements of variance in the MS signal, we have analysed the frequency responses of the MS/ARM and $M S_{C F B}$ records of this core as well as its MS record.

\section{Core: D9812}

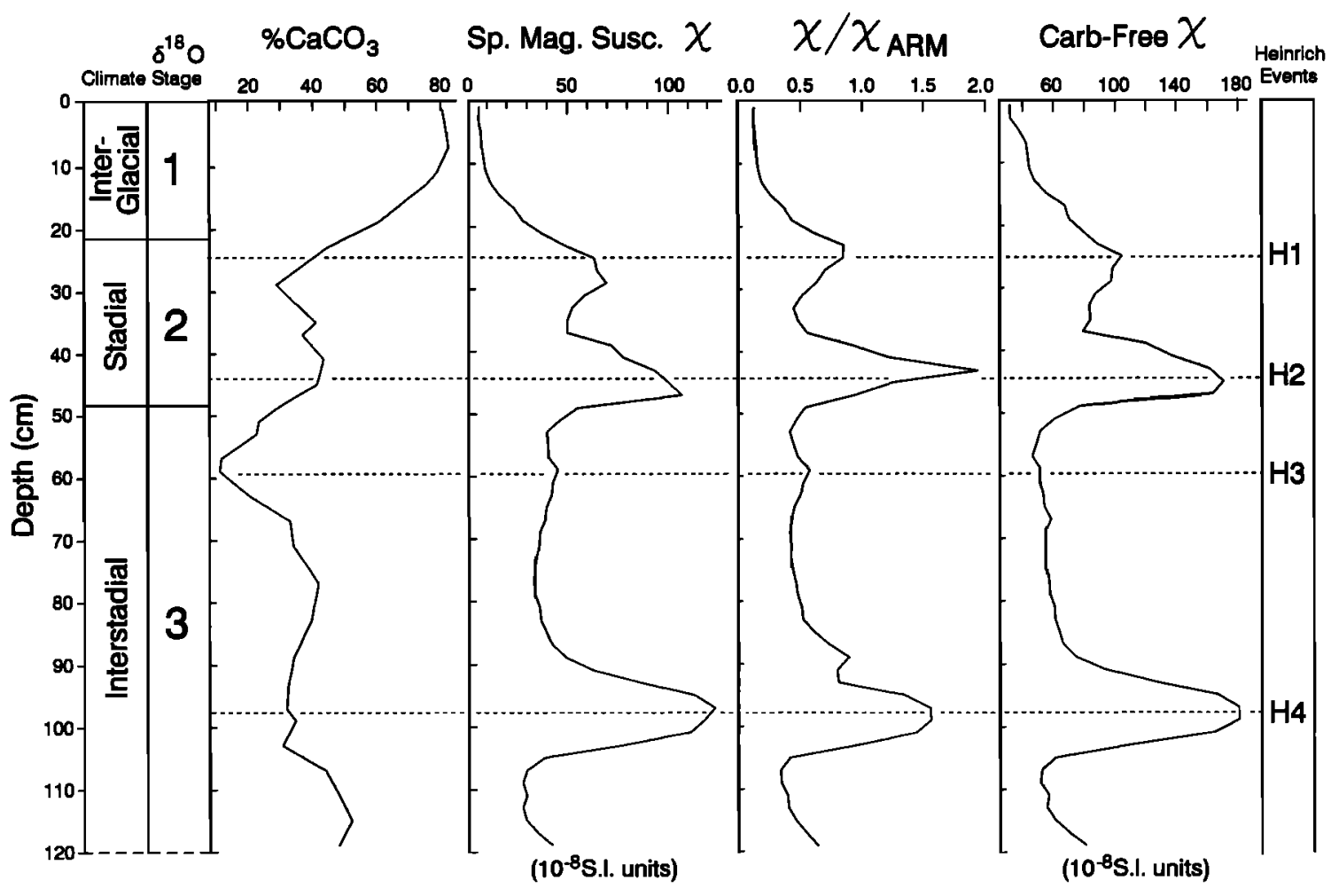

Figure 10. Relationships between carbonate content, bulk sediment MS $(\chi)$, and carbonate-free rock magnetic properties $\left(\chi / \chi_{\mathrm{ARM}}\right.$ and $\left.\chi_{\mathrm{CPB}}\right)$ of IOS Kasten core D9812, taken from within Ruddiman and McIntyre's [1976] zone of "heavy" IRD input during glacials. Note that H3 is associated with a clear dropstone layer in this core, as well as with a distinct low in $\% \mathrm{CaCO}_{3}$ content, but is not distinguished by a significant change in the rock magnetic properties of the sediment. 
We obtained an age model for core S8-79-4 in the following way. Oxygen isotope profiles are available for all of the King's Trough Flank gravity and piston cores, including core S8-79-4 [Kidd et al., 1983]. The $\delta^{18} \mathrm{O}$ records of the piston cores (e.g., Figure 3), and of core S8-79-5 are of particularly high resolution, as noted earlier. Between these $\delta^{18} \mathrm{O}$ records it is possible to recognise 29 of the isotopic events defined by Prell et al. [1986] in the SPECMAP $\delta^{18} \mathrm{O}$ stack, for the interval encompassed by the record of core S8-79-4, thus allowing us to derive the equivalent ages for these events in the SPECMAP timescale [Imbrie et al., 1984]. Having identified these events in the highresolution King's Trough Flank core $\delta^{18} \mathrm{O}$ records, the data were then extrapolated to the equivalent stratigraphic positions in core S8-79-4 (if not identified directly in the $\delta^{18} \mathrm{O}$ profile of this core) by means of correlation between cores based on their MS records (e.g., Figures 2 and 3). Further stratigraphic control was obtained by the planktonic foraminiferal and coccolith assemblage zonation of the cores by Weaver [1983; Kidd et al., 1983]; the ${ }^{230}$ Th-excess dating of core S8-79-8 [Booty, 1985]; and the ${ }^{14} \mathrm{C}$ dating of Heinrich events in BOFS core 5K (Manighetti et al., submitted manuscript, 1994), which were again extrapolated to core
S8-79-4 by means of MS correlations (e.g., Figures $2 \& 4$ ).

Since the basis of the age model for core S8-79-4 is extrapolation of the SPECMAP timescale as described above, we have analyzed the frequency-domain variability in its rock-magnetic time series by means of cross-spectral analysis of these records relative to the stratotype SPECMAP $\delta^{18} \mathbf{O}$ stack (Figure 11). The techniques used for this analysis are based on standard, Blackman-Tukey methods [e.g., Jenkins and Watts, 1968, p. 209-257], and followed exactly the procedure described by Imbrie et al. [1989, 1992]. The programs we used for cross-spectral analysis were developed by J. J. Morley for use by the SPECMAP project group [e.g., Morley and Shackleton, 1984; Imbrie et al., 1984]. The interval length of the time series analysed from core S879-4 was $0-210 \mathrm{ka}$, resampled at 2-kyr intervals by gaussian interpolation (104 data pairs). The average accumulation rate of the core is $1.134 \mathrm{~cm} \mathrm{kyr}^{-1}$, and the core was sampled at $2 \mathrm{~cm}$ intervals, thus yielding an average sample resolution of $1.764 \mathrm{kyr}$, and a Nyquist period of $3.527 \mathrm{kyr}$. Prior to analysis, prewhitening of the time series was not thought necessary, but any nonstationarity was eliminated by applying a linear detrend to the data.

The upper plots in Figure 11 contrast the spectral charac-

\section{Core: S8-79-4, 0 - $210 \mathrm{ka}$}

A. Magnetic Susceptibility $(\chi)$

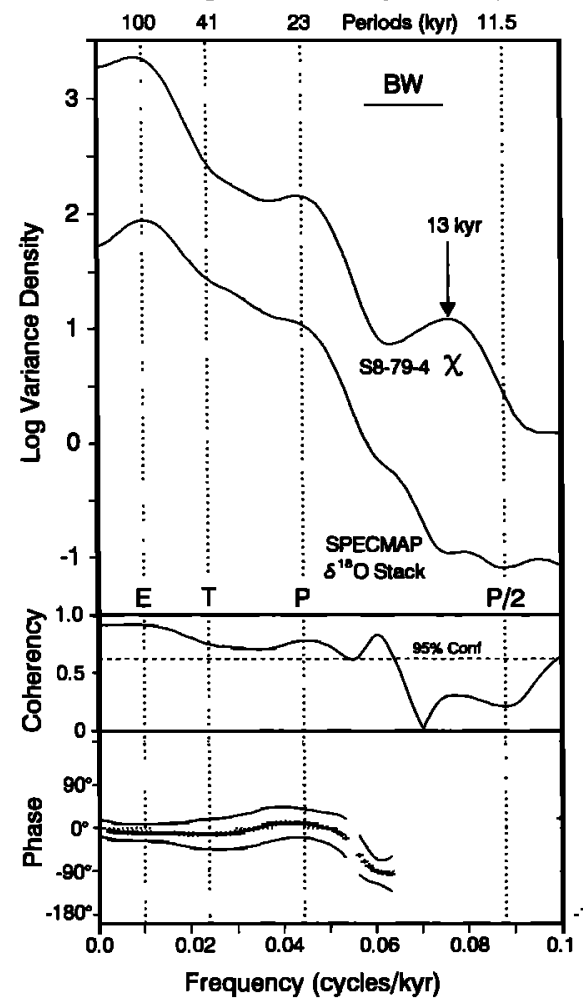

B. MS/ARM Ratio $\left(\chi / \chi_{\text {ARM }}\right)$

$\begin{array}{llll}100 & 4 t & 23 & \text { Periods (kyr) } 11.5\end{array}$

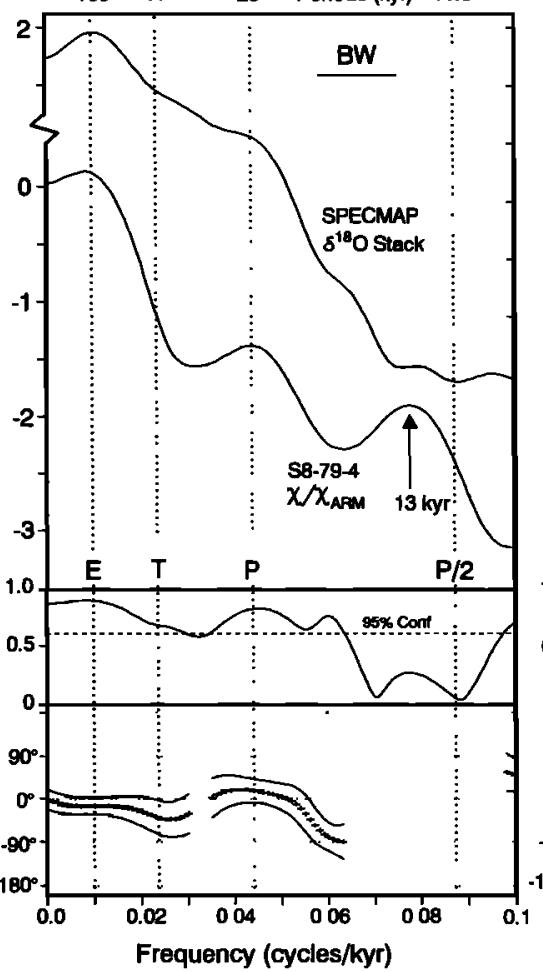

C. Carbonate-Free Mag. Susc. $\begin{array}{lllll}100 & 41 & 23 & \text { Periods (kyr) } & 11.5\end{array}$

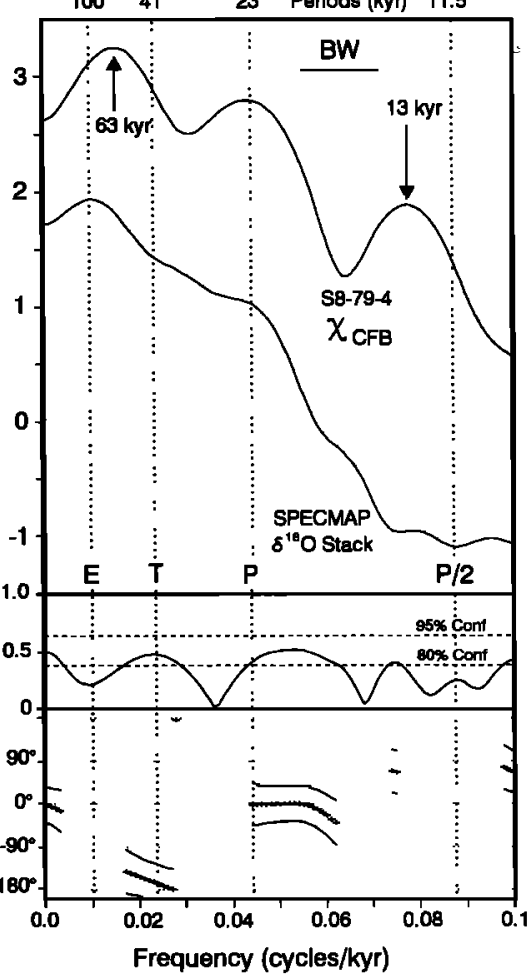

Figure 11. Cross-spectral analyses of three IRD-related rock-magnetic time series from King's Trough Flank core S8-79-4 (0 - $210 \mathrm{ka}$, at $2 \mathrm{kyr}$ intervals $)$, relative to the SPECMAP $\delta^{18} \mathrm{O}$-stack stratotype of Imbrie et al. [1984]. (A) Bulk MS $(\alpha)$ versus SPECMAP $\delta^{18} O$ stack; (B) MS/ARM $\left(\alpha / \chi_{\text {ARM }}\right)$ versus SPECMAP $\delta^{18} O$ stack; (C) Carbonate-free MS $\left(\chi_{\mathrm{CPB}}\right)$ versus SPECMAP $\delta^{18} O$ stack. E, eccentricity; $T$, tilt (obliquity); P, precession; P/2, first harmonic of $23 \mathrm{kyr}$ precession period; BW, bandwidth. Note that in phase plots the only data which are shown correspond to coherency values which are $>95 \%$ significant $\left(>80 \%\right.$ in the case of $\mathrm{MS}_{\mathrm{CFB}}$ ). 
teristics of each of the three magnetic properties analysed in core S8-79-4 with those of the SPECMAP $\delta^{18} \mathrm{O}$ stack [Imbrie et al., 1984]. In each case, for the relatively short interval analysed here, the resolution of primary orbital responses is better in the spectra of the magnetic parameters than it is in the spectrum of the SPECMAP $\delta^{18} O$ stack. Note that eccentricity (where present) and precessional power in the spectra of the magnetic parameters culminates at exactly the 100- and 23-kyr periods, and in the case of MS and

MS/ARM, shows high ( $>95 \%$ significant) coherency and near-zero phase contrast with the SPECMAP $\delta^{18} O$ stack at all primary orbital frequencies. This shows that bulk sediment MS (and MS/ARM) covaries directly, and in-phase with global benthic $\delta^{18} \mathrm{O}$ (ice-volume) fluctuations. It also means that the age model for this core is accurate for the primary orbital responses, which are the frequencies to which, in effect, we tuned our initial $\delta^{18} \mathrm{O}$ stratigraphies, by the procedure of extrapolating the SPECMAP timescale, as outlined above. Therefore, any other significant responses observed in these spectra must be real, and not an artifact of age model error.

The prominent 13-kyr period which can be seen clearly in each of the three spectra of the rock-magnetic parameters, and which is absent from that of the SPECMAP $\delta^{18} \mathrm{O}$ stack, must therefore correspond to a significant high-frequency component of variance in ferrimagnetic concentration and grain size. Each of the three spectra in Figure 11 are cut off at a frequency of 0.1 cycles/kyr because there are no significant peaks in variance density in these records which occur at frequencies higher than this. Thus the 13-kyr signal probably corresponds to the high-frequency IRD events in core S8-79-4. However, the fact that this signal does not vary at a period corresponding to a precessional half-cycle (or first harmonic), as suggested by Heinrich [1988], nor at a period of about $7 \mathrm{kyr}$, as suggested recently by MacAyeal [1993a, b], is not significant in this instance. This is because the record of core S8-79-4 is short, and IRD event H3 is absent from this core (and from all the King's Trough Flank cores). Also, two further Heinrich events are missing from this core, namely $\mathrm{H} 7$ and $\mathrm{H} 9$, though these also were not manifested by a significant response in \%IRD sand in Heinrich's own cores (e.g., Me69-17, Figure 3). Naturally, the absence of one or more IRD pulses from a record as short as this will significantly affect the apparent periodicity of the IRD events which are present.

In the spectrum of $\mathrm{MS}_{\mathrm{CFB}}$, the $100 \mathrm{kyr}$, orbital eccentricity-related signal is absent because this component of variance in bulk MS is largely contributed by oscillations in carbonate content of the sediment which are partly driven by IRD-dilution effects. The $63 \mathrm{kyr}$ period in the $\mathrm{MS}_{\mathrm{CPB}}$ spectrum may represent a combination tone between a primary orbital response in this time series (e.g., the 23-kyr precessional cycle) and the 13-kyr non-Milankovitch cycle, since there is no coherency with the SPECMAP stack at this frequency. There is an $80 \%$ significant peak in coherency with the SPECMAP stack at the $41 \mathrm{kyr}$ orbital obliquity period, where the cycle in $\mathrm{MS}_{\mathrm{CPB}}$ is $180^{\circ}$ phase-shifted (antiparallel) relative to the SPECMAP stack. However, a combination tone of the 23- and 13-kyr cycles, as seen in the $\mathrm{MS}_{\mathrm{CFB}}$ spectrum, would occur at a period of $40.7 \mathrm{kyr}$, which may account for the coherency with the SPECMAP stack at this near-orbital frequency. For frequencies in the Milankovitch band, therefore, it appears that variations in ferrimagnetic concentration and grain size related to IRD deposition respond chiefly to eccentricity-modulated precessional forcing. However, there is also a significant highfrequency component of variance in these magnetic properties which occurs at the non-Milankovitch period of 13 kyr.

LGM/Holocene MS Ratios in the NE Atlantic: A TimeSlice Reconstruction

Having established the rationale for using the MS signal of NE Atlantic sediments as a proxy for their IRD content, we can now proceed to utilise this relationship in a paleoceanographic context. Here we attempt a spatial analysis of IRD-related changes in MS of NE Atlantic sediments by mapping the variation in glacial/interglacial MS ratios in the region between $35^{\circ}$ and $70^{\circ} \mathrm{N}$, for the LGM relative to the "most recent" Holocene ( $\approx$ core top). This reconstruction (Figure 12) is based largely on two sets of isochronous samples which were taken by Zimmerman [1982] from the same cores, and sampling horizons, as were used by the CLIMAP project group [e.g., Cline and Hays, 1976]. Zimmerman's study contrasted the recent Holocene and LGM variations in the relative abundance of clay minerals and quartz in the North Atlantic. The LGM time-slice sample depths are listed in the classic CLIMAP study by McIntyre et al. [1976]. Only those cores with their sediment/water interfaces preserved in tact were sampled, so that core top data are reasonably representative of present day conditions. Stratigraphic control in the cores is provided by $\delta^{18} \mathrm{O}$ profiles, ${ }^{14} \mathrm{C}$ dating, and, in the case of a few cores which lacked such information, $\% \mathrm{CaCO}_{3}$ records used as a proxy for $\delta^{18} \mathrm{O}$ profiles, or to correlate with sites where such data are available. Details of the exact procedure by which stratigraphic control was obtained in order to constrain sampling of the LGM time-slice are given in the paper by McIntyre et al. [1976], and in other CLIMAP studies referred to therein [p. 46].

For the present study, we have augmented the MS data from Zimmerman's samples with MS data from the same horizons in the 17 cores examined here, plus similar data from several other NE Atlantic cores we have measured in the past, or have obtained from other workers (see Table 1, and accompanying text above). In common with the CLIMAP study by McIntyre et al. [1976], the maps published by Zimmerman [1982] covered an area between latitude $5^{\circ} \mathrm{S}$ and $70^{\circ} \mathrm{N}$, and longitude $20^{\circ} \mathrm{E}$ and $85^{\circ} \mathrm{W}$, based on 88 sample sites. The sample density within this region, however, is rather inconsistent. We have therefore selected a smaller NE Atlantic region within which sample density is more uniform and relatively high (Figure 1), especially when our additional core data are added to those from the Zimmerman sample pairs. It should also be noted that the interpolation of isolines in Figure 12 is guided by data from sample sites beyond the limits of the area shown in this map, or listed in Table 1 above. Within the area shown in Figure 12, our LGM reconstruction is based on a larger number of sample sites than any other study of a similar kind referred to in this paper. 


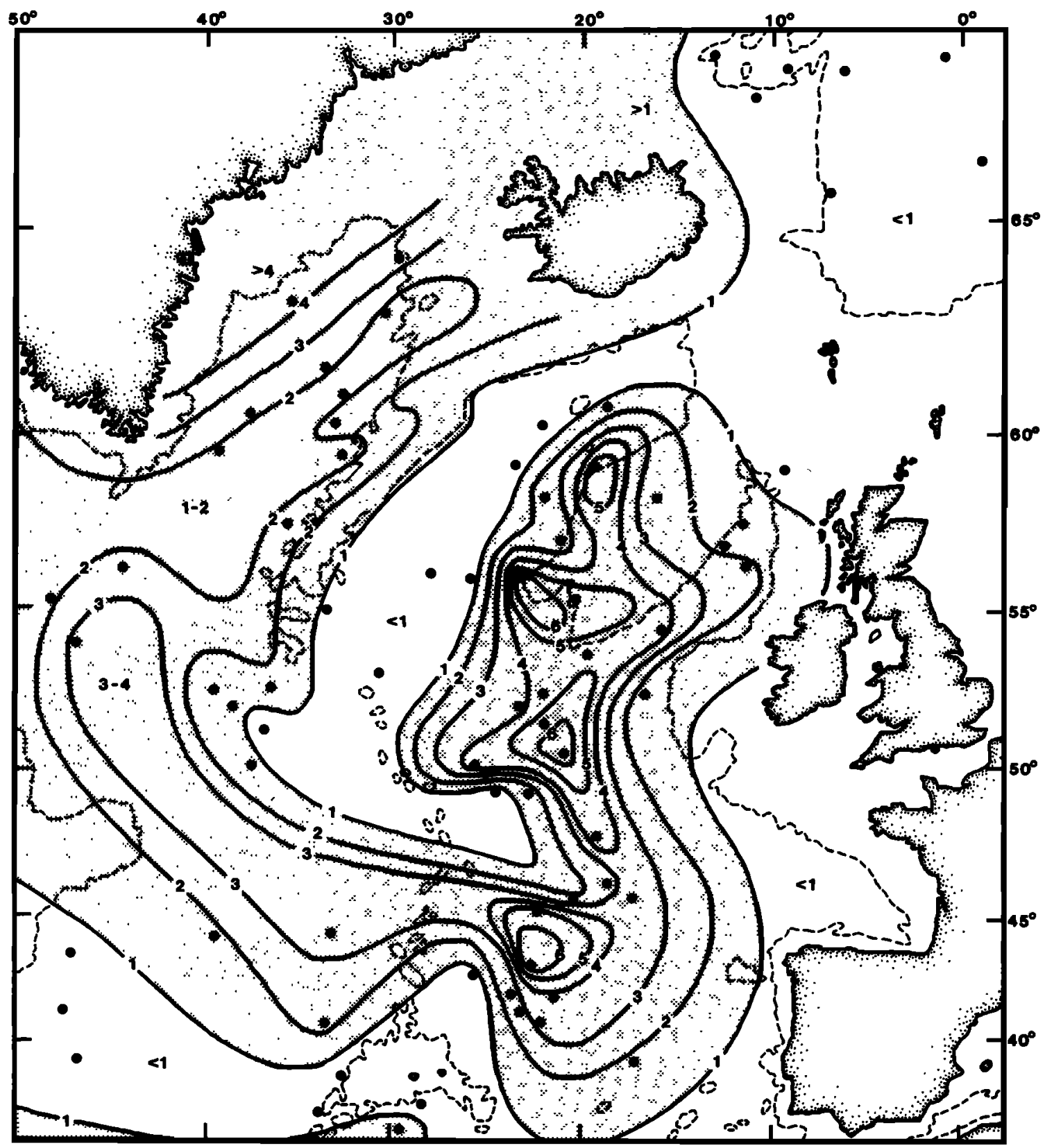

Figure 12. Time-slice reconstruction of the MS values of North Atlantic deep-sea sediments for the LGM $(\sim 18-19 \mathrm{ka})$ relative to the present-day. Variations in LGM/Holocene MS-ratios reflect differences in the flux of terrigenous detrital magnetic minerals between the present day and glacial time slices, due mainly to deposition of ice-rafted detritus. The MS-ratio values upon which this map is based are listed in Table 1 , with a key to the coring stations also listed, and indicated in the location map (Figure 1). Dashed line corresponds to 1000 Fathom isobath.

It is very important to note that, when using MS data as a proxy to map variations in the IRD content of deep-sea sediments, it is only valid to use ratios of MS values for a given time slice horizon (e.g., the LGM), normalised by the MS value for some other reference horizon (e.g., the present day). Maps showing the variation in MS of deep-sea sediments for the present day and the LGM separately [Robinson 1986b], though displaying some trends which relate to oceanographic variables, are complicated by the influence of major sources of magnetic mineral imput, such as in volcanic terrains, which dominate the distribution of isolines in both time-slice reconstructions. A CLIMAP-style MS anomaly map for the LGM, based on the absolute difference in MS values between the present day and the LGM, will not entirely eradicate this problem. This is because the anomaly value being mapped is $\chi$, a mass-specific (concentration dependent) parameter. Sites affected by volcanic contributions to the sediment (directly or via ice-rafting, or both) 
may exhibit a large difference in MS values of the sediment between the present-day and the LGM. However, the ratio of these values may not be significantly different to that of sites in the same region (i.e., with similar rates of IRD deposition) which are not affected by volcanic input, and which thus have much lower LGM and present-day MS values, and a correspondingly lower difference, in absolute terms, between these values. This problem is most simply obviated by plotting the distribution of $\mathrm{MS}_{\mathrm{TIME}}$ SLICE $/ \mathrm{MS}_{\text {REFERENCE HORIzoN }}$ ratios, which reflect only the changes in MS values of the sediment between each time slice which are due changes in oceanographic and/or atmospheric processes of sediment dispersal. Another importmant attribute of this approach is that it allows us to combine whole-core volume MS $(\kappa)$ data with discretesample specific MS $(\chi)$ data, provided that the same kind of data are available for both time-slice horizons at each site. It is invalid to mix whole-core $\kappa$ data with $\chi$ data from dried, powdered samples, unless the wet volume to dry sediment weight relationship of the samples is known.

The range of variation in LGM/Holocene MS-ratios mapped in Figure $12(<1$ to $>6)$ is clearly much smaller than the range associated with the transects in Figure 6 (i.e., $<1-27$ ). This is because the MS-ratio values for the latter were based on using the Holocene climatic optimum ( $\mathrm{HCO}$, $\sim 6 \mathrm{ka}$ ), rather than the core top or present-day, as a reference horizon. The MS of the HCO time-slice, in all of the cores investigated in this study, is three or four times lower than that of the present-day samples from the same cores (though the difference in absolute terms is small by comparison with the difference between the Holocene and LGM time slice values). This makes LGM/HCO MS-ratios much more sensitive to differences in IRD input than LGM/ present-day MS-ratios.

The shaded areas in Figure 12 depict regions where LGM/Holocene MS-ratios are $>1$, that is, where the MS of the sediment at the LGM was higher than it is at the present time. Unshaded areas depict regions with no change in sediment MS values, or where MS values are higher today than they were at the LGM. Within the shaded areas the contours delineate trends in MS-ratios which infer patterns of IRD deposition and thus surface currents, with high MSratios indicating regions of relatively more intense IRD input. It is important to note, however, that high MS-ratios may not appear in certain regions of intense LGM ice-rafting activity because present-day currents also transport significant numbers of melting icebergs in these areas (e.g., south of Newfoundland and Nova Scotia). Also, the spatial variation in MS-ratios mapped in Figure 12 will reflect mainly the distribution of IRD containing at least traces of mafic components. Ice-rafted materials derived exclusively from mature sandstone or limestone source regions, for example, may be not be adequately represented in this reconstruction. We have not limited the area contoured in Figure 12 to take into account either the lower sea level of the LGM, or the areas of permanent pack-ice cover of the sea.

The spatial variation in MS-ratios $>1$ shows a continuous, hook-shaped band extending from the Greenland Sea around Iceland and the Denmark Strait, passing southwest through the Irminger Basin and Reykajanes Ridge, then branching northwest into the Labrador Sea and southeast into the Newfoundland Basin. Here the band extends further east into the West European Basin, where it then appears to veer north (possibly with a minor southern branch), and reach as far north as the center of the Iceland Basin. In general, the pattern of MS-ratios > 1 clearly follows the cyclonic trend of LGM surface currents north of the polar front, as originally suggested by Ruddiman and Glover [1972]. The paleoceanographic implications of this LGM/Holocene MSratio distribution are discussed in more detail in the next section.

Within the shaded areas of Figure 12, regions where the MS values of sediments deposited at the LGM were more than twice their present-day values include virtually all of the West European Basin, where it appears that most melting of icebergs and deposition of IRD occurred, with several local depositional maxima characterized by LGM/Holocene MSratios of $>5$ or $>6$. There is also a band of high MS-ratios following the trend of the western Reykjanes Ridge south of Iceland (a major iceberg source area at the LGM) veering southeast in the Newfoundland basin, and ultimately feeding into the region of high MS-ratios in the West European Basin. An additional band of high MS-ratios occurs in the Denmark Strait and northwestern Irminger Basin, apparently following the Greenland continental margin, with MS-ratios increasing towards the SE Greenland coast. This coastline marks the position of the marine ice margin of the Greenland Ice Cap at the LGM, and this was then a major source region for icebergs in the North Atlantic. The high MSanomalies here, however, may also partly reflect more proximal glaciomarine sedimentary process than ice-rafting, as well as the effects of lowered sea levels, possibly resulting in shelf sediment erosion and instability leading to massflows off the continental margin.

\section{Discussion}

\section{Time Series MS Data and Heinrich Events}

In the North Atlantic at least, as the results of the present study have shown (Figures 8 - 10), the apparent relationship between variations in the MS signal and lithological composition of deep-sea sediments is essentially coincidental rather than directly causal. Variations in bulk sediment MS here are largely controlled by the amount and type of IRD in the sediment. Ice-rafted input, however, is also chiefly responsible for diluting the biogenic fraction, though bulk MS variations are not merely related to a simple carbonate dilution mechanism. There is a more direct rock-magnetic relationship between the MS signal of the bulk sediment and its IRD content. The MS signal of our NE Atlantic cores depends mainly on variations in the amount and type of detrital ferrimagnetic material which usually occurs as a trace component within the lithogenic fraction of the sediment. Often, there are significant variations in the MS of the lithogenic fraction (i.e., $\mathbf{M S}_{\mathrm{CrB}}$ ) which reflect changes in the concentration and grain size of the ferrimagnetic minerals it contains, associated with differences in the provenance and accumulation rates of IRD. Most of the IRD-rich (Heinrich) layers in NE Atlantic sediments are quite distinctive in terms 
of their sedimentological and rock-magnetic composition, relative to the intervening sediment within glacial horizons, the detrital fraction of which is also dominated by ice-rafted material.

These results are consistent with the data of Broecker et al. [1992] and Bond et al. [1992], who showed that the mineralogical composition and $\mathrm{K}$-Ar ages of detrital grains within Heinrich IRD layers of North Atlantic deep-sea cores were quite different from those of the ambient sediment of glacial horizons. The differences pointed to a source in eastern Canada (limestone of the Hudson Bay area, and archaean granite of the Canadian Shield) for detrital components of Heinrich layers $\mathrm{H} 1, \mathrm{H} 2, \mathrm{H} 4$, and $\mathrm{H} 5$. This suggested that these events were attributable to periodic disintegration of the grounded sea-ice margin of the Laurentian Ice Sheet in the Hudson Bay region. Recently, MacAyeal [1993a, b] has proposed a nonorbital model, invoking thermodynamic controls on a process of gradual build-up, followed by catastrophic disintegration, to explain how and why the marine margin of this ice sheet regularly surges, with a periodicity of about 7000 years. The surges generate large armadas of icebergs which flow out of the Labrador Sea into the North Atlantic, thus depositing the Heinrich IRD layers.

Both Broecker et al. [1992] and Bond et al. [1992] noted that the source-signature of IRD associated with $\mathrm{H} 3$ is different from that of the other Heinrich events. This was also corroborated by Grousset et al. [1993], who measured the ${ }^{87} \mathrm{Sr} /{ }^{86} \mathrm{Sr}$ ratios of Heinrich layers in their NE Atlantic cores, and suggested an Arctic provenance for the $\mathrm{H} 3$ event. In the present study, and also in a recent study by Lebreiro et al. [in press], it is clear that both the MS signal and other sedimentological properties of $\mathrm{H} 3$ event horizons differ significantly from those of the other Heinrich events. The areal extent of the H3 IRD layer is also more limited than that of the other Heinrich events. Where independent, sedimentological data confirm the presence of $\mathrm{H} 3$ in a core, its MS signal is generally much weaker than that of $\mathrm{H} 1, \mathrm{H} 2$, H4, and H5 (and also the other IRD events originally identified by Heinrich [1988] numbered 6, 8, 10, and 11, which are associated with cold isotopic events (Figure 3)), and is often indistinguishable from the MS signal of the background IRD in glacial horizons. This possibly indicates a common source of origin for the $\mathrm{H} 3$ event and the background IRD. If this is indeed the case, then it must cast some doubt on the ability of MacAyeal's model to explain the existence and frequency of all Heinrich events, since this model is based solely on the dynamics of the Laurentian Ice Sheet. Clearly, if other Heinrich events occur at approximately the same frequency, but are derived from different sources, this must favour an external (i.e., orbital) forcing mechanism, as originally proposed by Heinrich [1988]. In Heinrich's model, high frequency IRD pulses were thought to occur each half period of an orbital precession cycle, that is, at a period of about $11 \pm 1 \mathrm{kyr}$. In the present study, the only significant high frequency component of variance in spectra of IRD proxies occurred at a period of $13 \mathrm{kyr}$. However, the shortness of our records, and the absence of one or more Heinrich events in the core analysed, possibly explains this difference. More significantly, in a recent study by Robinson and McCave [1994], a spectral analysis of a carbonate-free MS record from DSDP site 610 (cf. Figure 5), for the interval $0.5-1.2 \mathrm{Ma}$ (sampled every $2.5 \mathrm{kyr}$ ), revealed a significant high-frequency component of variance at exactly the precessional half-cycle period of $11.5 \mathrm{kyr}$, as predicted by Heinrich [1988].

\section{Time Slice MS Data: Paleoceanographic Implications of} LGM/Holocene MS-Ratios

Our map showing the variation in $\mathrm{MS}_{\mathrm{LGM}} / \mathrm{MS}_{\mathrm{HOLOCENE}}$ ratios (Figure 12) allows us to infer changes in surface water circulation patterns for the North Atlantic about 19,000 years ago, relative to the present day. This is because, as we demonstrated earlier, the MS signal of deep-sea sediments within this region provides a reliable proxy for their IRD content. Hence the difference between the MS values for the LGM and present-day time slices, in each of the cores used to reconstruct the LGM/Holocene MS-ratio map, are due mainly to changes in the influx of IRD containing at least traces of mafic components (and partly to differences in biogenic productivity) at each site. Variations in LGM/ Holocene MS-ratios therefore indicate changes both in the intensity of ice-rafting activity and in the patterns of iceberg dispersal. These, in turn, are related to changes in the volume and extent of the northern hemisphere ice sheets; the resulting shifts in position of the polar front; and, in consequence, the changing patterns of surface currents.

Previous paleoceanographic reconstructions of IRD-related parameters similar to that shown in Figure 12 have been attempted in several studies [e.g., Ruddiman 1977a, b; Kolla et al., 1979; Ruddiman and McIntyre, 1981; Zimmerman, 1982; Fillon et al., 1981; Fillon, 1985; Smythe et al., 1985; and Grousset et al., 1993]. Of these, Zimmerman's maps naturally compare favorably with the LGM/Holocene MSratio distribution shown in Figure 12 (which is based largely on the same samples), but in the region north of $45^{\circ} \mathrm{N}$, our MS-ratio map resembles even more closely (where sample coverage allows) Kolla et al.'s [1979] 18 ka-glacial anomaly map for quartz content. Most differences between these reconstructions can be ascribed almost entirely to the subjective procedure of interpolating isolines in areas of sparse data. Kolla et al. [1979] were clearly influenced in this regard by the reconstructions of Ruddiman [1977a, b], which feature a latitudinal distribution of isolines for IRDsand imput in the region north of the Iberian Peninsula, to as far north as $55^{\circ} \mathrm{N}$, and west to $35^{\circ} \mathrm{W}$. Consequently, Kolla et al. [1979] (and Zimmerman, 1982), in the absence of data to the contrary, favored linear belts of high LGM quartz anomalies arranged latitudinally, with two areas of high anomalies north of $30^{\circ} \mathrm{N}$, separated by a narrow band of lower anomaly values north of the Iberian Margin, trending east-west between the Bay of Biscaye and $40^{\circ} \mathrm{W}$ (centered on the position of the LGM polar front). In our LGM/Holocene MS-ratio map, the data suggest a connection between these two regions of high IRD input in the West European Basin. Kolla et al. [1979] also show a broad band of high LGM quartz-anomalies following the coastline of SE Greenland, extending into the Labrador Sea. However, they have no data to suggest a connection between this region of high LGM anomalies and the southernmost belt of high anomalies 
alluded to above, which occurs in the NE Atlantic, south of the LGM polar front. Again, we have several cores from this region, and data from these suggest a connection between the NW Atlantic belt of high IRD input trending meridionally between the Denmark Strait and the Labrador Sea, and the NE Atlantic IRD belt trending latitudinally between the Grand Banks region and the Iberian Margin.

Our interpretation of the LGM/Holocene MS-ratio map (Figure 12) is summarized in Figure 13, which shows a simplified circulation cartoon depicting the general trends of surface currents and iceberg dispersal trajectories in the LGM North Atlantic. This interpretation is based largely on the reconstructions by Fillon et al. [1981], and Fillon [1985], for the $\delta^{18} \mathrm{O}$ stage 2 interval between $25 \mathrm{ka}$ and 13 ka (25 - $16 \mathrm{ka}$ in the later paper), which corresponds most closely to our LGM time-slice, modified according to the patterns of LGM/Holocene MS-ratios mapped in Figure 12.
As with our MS-ratio map, we have not taken into account the effects of lower sea levels or permanent pack-ice cover on the surface current patterns. The patterns of iceberg distribution reflect the surface current regime of the warm spring/summer seasons of the LGM. This is when sea surface temperature and thus melting of icebergs is at a maximum [Dowdeswell and Murray, 1990], and the extent of seasonal pack-ice cover is minimal. The deposition of IRD is therefore most ubiquitous at this time of year. It should also be noted, of course, that the surface currents occupy broad belts, separated by convergence zones, rather than linear flow trajectories as depicted in this simplified reconstruction.

Figure 13 is modified after Fillon et al.'s [1981] reconstruction for the interval $25-13 \mathrm{ka}(25-16 \mathrm{ka}$ in Fillon's [1985] version). However, these authors also published paleoceanographic maps for three other late Pleistocene

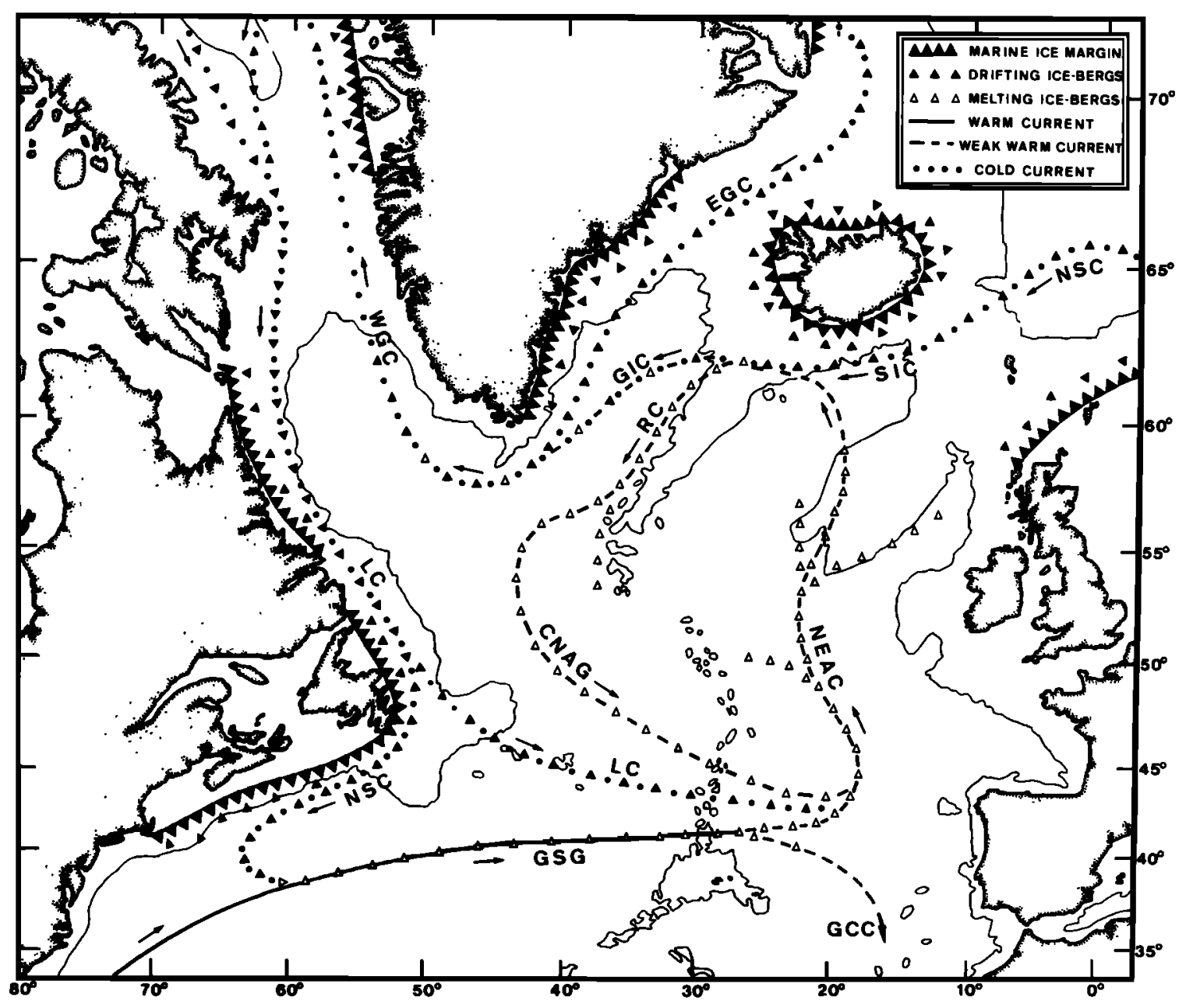

Figure 13. Generalized paleoenvironmental reconstruction of the surface currents and iceberg dispersal patterns in the North Atlantic at the LGM ( 18-19 ka) (modified after Fillon et al.'s [1981] reconstruction for $\delta^{18} \mathrm{O}$ stage 2, according to the patterns of LGM/Holocene MS-ratios mapped in Figure 12). EGC, East Greenland Current; WGC, West Greenland Current; LC, Labrador Current; NSC, Nova Scotia Current; GSG, Glacial Subtropical Gyre; GCC, Glacial Canaries Current; CNAG, Central North Atlantic Gyre; NEAC, Northeast Atlantic Current; RC, Reykjanes Current; GIC, Glacial Irminger Current; SIC, South Iceland Current; NSC, Norwegian Sea Current. Continental margins and oceanic ridges are delineated by the 1000 fathom isobath. 
intervals, one of which was for the interval $13-9.8 \mathrm{ka} \mathrm{(16} \mathrm{-}$ $9.8 \mathrm{ka}$ in Fillon's [1985] version), which corresponds to the Phase IIIa interval of Termination I (pre-Younger Dryas cooling event) in Ruddiman and McIntyre's [1981] scheme, and which immediately follows Fillon et al.' $s[1981] \delta^{18} \mathrm{O}$ stage 2 reconstruction (Phase I of Ruddiman and McIntyre [1981]). We mention this particular reconstruction here because it agrees with our map of LGM/Holocene MS-ratios (Figure 12) almost perfectly, without any need for modification. However, as there are extreme differences in paleoceanography between the Phase I $(\approx$ LGM) and Phase IIIa intervals of Termination I [Ruddiman and McIntyre, 1981], we felt constrained to base our reconstruction on Fillon et $a l$.'s [1981] paleocirculation map for $\delta^{18} \mathrm{O}$ stage 2 instead.

The main change we have made to Fillon et al.'s [1981] $\delta^{18} \mathrm{O}$ stage 2 reconstruction is that we suggest the presence of a fully-cyclonic, central North Atlantic gyre (CNAG), north of the LGM polar front (as originally deduced by Ruddiman and Glover [1972]). This gyre is partly fed by warm, subtropical waters from south of the polar front, and partly by the cold, Labrador Current (LC). The LC carries icebergs south from Baffin Bay, entraining further icebergs from the marine margin of the Laurentian Ice Sheet in the Hudson Strait and Labrador shelf region. The current then bifurcates off the coast of Newfoundland, with one branch flowing east into the central North Atlantic, ultimately feeding into the CNAG, as noted above. This is the current which carries icebergs associated with Heinrich events H1, $\mathrm{H} 2, \mathrm{H} 4$ and H5, except that during these episodes, the West Greenland Current (WGC) flows in the opposite direction to that indicated in Figure 13, and thus carries further icebergs south from Baffin Bay [Fillon, 1985]. (A band of high LGM MS-anomalies can be seen clearly in Figure 12 to follow the trend of both the East and West Greenland Currents.) The second branch of the LC, termed the Nova Scotia Current (NSC) in Figure 13, flows around the Laurentian sea ice margin of Newfoundland and the Nova Scotian continental shelf, thus collecting more ice bergs, which are then fed into the glacial subtropical gyre (GSG) as the currents converge. The GSG transports the icebergs eastward, directly across the North Atlantic, to beyond the Azores Ridge. In the West European Basin, northeast of the Azores, the GSG itself bifurcates, with one branch forming the south-flowing Glacial Canaries Current (GCC), as identified in the CLIMAP reconstructions of McIntyre et al. [1976]. This current transports some icebergs towards the Canary Basin, as indicated in the recent study by Labreiro et al. [in press] which identified Heinrich IRD layers in a core from the summit of Tore Seamount off the coast of Portugal. The other branch of the GSG flows north, where it converges with the cold waters of the LC to form a sluggish warm current, termed the Northeast Atlantic Current (NEAC) in Figure 13, which flows north towards the Rockall Plateau.

The NEAC carries large numbers of icebergs from the Labrador Sea and Nova Scotian sources, as described above. However, it also contains icebergs derived from Iceland and possibly the North European-Scandinavian Ice Sheet. This is because the NEAC ultimately converges with the Glacial Irminger Current (GIC) south of Iceland (SIC), thus collecting icebergs from Scandinavian and Icelandic sources, then branches off in the northern Irminger Basin to form a weak warm current which flows southwest along the line of the Reykjanes Ridge. This "Reykjanes Current" (RC) then veers east in the Labrador Basin, forming the southern limb of the CNAG, which eventually converges with the east-flowing LC and GSG in the West European Basin, northeast of the Azores. It is important to stress that Figure 13 is highly schematic, and we cannot possibly be as precise as to the exact nature or location of convergence of these currents as is implied by this map.

The NEAC thus transports very large numbers of melting icebergs derived from many sources. The current is warm and sluggish, leading to intense deposition of IRD in the West European Basin between $40^{\circ}$ and $60^{\circ} \mathrm{N}$, thus accounting for the very high LGM/Holocene MS-ratios in this region. Because the current is weak, local recirculations may develop, or perhaps the main trajectory of the current shifts at certain times (indicated in Figure 13 by plotting the dispersal patterns of melting icebergs as open triangles, but without indicating their trajectories with a dashed line). This accounts for the localised centers of melting implied by the areas of extremely high anomalies. A band of MS-ratio values of $<1$ passes through the Iceland Basin, connecting with the Norwegian Sea (Figure 12). This suggests either that there was not a fully-cyclonic recirculation in the central North Atlantic (but if not, then where does the warm water come from which feeds the south-flowing RC ?), or that all of the icebergs carried north by the NEAC melt prior to reaching the Iceland Basin. In Fillon et al.'s [1981] original reconstruction, a weak branch of the subtropical gyre is depicted flowing northeastwards between the Newfoundland Basin and the Iceland-Scotland ridge, and a second branch from this flows north to converge with the GIC south of Iceland. In both cases, however, the authors indicate that these currents do not transport any icebergs north of $50^{\circ} \mathrm{N}$. We therefore suggest that the NEAC converges with the SIC-GIC, but that this is not marked by high MS-anomalies because all of the icebergs which the NEAC carries melt prior to reaching latitude $62^{\circ} \mathrm{N}$.

The dominantly meridional pattern of isolines describing the variation in LGM/Holocene MS-ratios in the NE Atlantic, north of $45^{\circ} \mathrm{N}$ (Figure 12), fit the data better than alternative reconstructions which attempt to constrain the interpolation of isolines according to Ruddiman's [1977a] mainly latitudinal orientation of IRD belts in the NE Atlantic. In Ruddiman's [1977b] surface current model for the glacial North Atlantic, the east-flowing currents of the cyclonic gyre (CNAG) are depicted as flowing directly orthogonal to the NW European continental margin in the region between $47^{\circ} \mathrm{N}$ and $57^{\circ} \mathrm{N}$. This configuration was indicated in order to conform with the linear belts of high IRD sand accumulation rate in this region, mapped in the earlier study. We feel that a pattern of surface currents involving such a broad band flowing directly onshore is rather unlikely. The earlier circulation model featured in the CLIMAP reconstruction of Ruddiman and McIntyre [1976], based on tracing the dispersal patterns of ice-rafted volcanic ash [Ruddiman and Glover, 1972; Ruddiman and McIntyre, 1973], is more consistent with our modified version of Fillon et al.'s [1981] scheme (Figure 13), which is based on tracing 
the dispersal patterns of mafic mineral-bearing IRD using LGM/Holocene MS-ratios. Our data density in the crucial region between $47^{\circ} \mathrm{N}$ and $57^{\circ} \mathrm{N}$, and east of $20^{\circ} \mathrm{W}$, is better than that of Ruddiman, or of any other study cited above. We are therefore reasonably confident in our above interpretation (Figure 13) of the pattern of LGM/Holocene MSratios shown in Figure 12, which depicts a north-flowing current in the NE Atlantic carrying large numbers of icebergs derived from a variety of sources, most or all of which melt prior to reaching the Iceland Basin.

\section{Summary of Conclusions}

The MS signal of North Atlantic deep-sea sediments is frequently modulated by orbital-climatic forcing because of the well-established linkage in this region between changes in sediment composition and paleoclimate, via the mechanisms of biogenic carbonate productivity variations and dilution of the biogenic fraction by terrigenous detritus (also carbonate dissolution below the lysocline). Ice-rafting is by far the most important mechanism for delivering terrigenous detritus to pelagic regions north of $40^{\circ} \mathrm{N}$ during the Pleistocene, and the bulk of the ferrimagnetic fraction of deep-sea sediments of this region is of terrigenous detrital, hightemperature origin. Other magnetic components, if present, contribute very little to the MS signal of the bulk sediment.

However, in the NE Atlantic at least, the apparent relationship between variations in the MS signal and lithological composition of deep-sea sediments is not merely a function of simple, carbonate-dilution effects. There is also a more fundamental linkage between the MS signal and the IRD content of the sediment. Changes in the provenance and accumulation rates of IRD in the sediment effect changes in the concentration and grain size of ferrimagnetic components within the lithogenic fraction. In particular, layers rich in ice-rafted terrigenous sand within glacial horizons of cores from this region are characterized by a significant increase in the concentration and relative proportion of coarse grained (multidomain) ferrimagnetic particles (to which MS is particularly sensitive), relative to the ambient sediment of glacial horizons. This is because ice-rafting is the only mechanism capable of transporting sand-sized terrigenous detritus to pelagic environments, and IRD sand has a high potential for preserving coarse ferrimagnetic grains as components of polycrystalline fragments of basic igneous rocks or their sedimentary derivatives.

Glacial-interglacial variations in the background level of the MS signal of NE Atlantic sediments are driven by changes in carbonate productivity and dilution (mainly by IRD) in response to $100 \mathrm{kyr}$, orbital eccentricity, and subsidiary $23 \mathrm{kyr}$ precessional climatic forcing. However, individual peaks in MS within glacial horizons of cores from this area correlate with high-frequency ice-rafting episodes termed "Heinrich events" by Broecker et al. [1992]. In the cores analysed in this study, these high-frequency IRD pulses appear to exhibit a non-orbital periodicity of around $13 \mathrm{kyr}$ (possibly because the record we analysed was short and at least one Heinrich IRD event was absent). In the NE Atlantic region between $45^{\circ}$ and $53^{\circ} \mathrm{N}$, Heinrich IRD events (except H3) are associated with an extremely strong MS signal, that is, greater by at least an order-of-magnitude than the background level of MS in glacial horizons. This is because the sediment here contains a high proportion of sandy IRD, rich in multidomain ferrimagnetic material, and very little biogenic carbonate. Heinrich Event $H 3$, in contrast, does not contain a significantly higher proportion of ferrimagnetic material than the ambient sediment of glacial horizons, suggesting that it is derived from a similar source to that of the background IRD in these intervals. Outside the zone of high IRD influx, Heinrich events are still recognisable in MS profiles, but only as small peaks in MS above the background levels for glacial horizons.

In Heinrich's [1988] original study, however, 12 IRD events were recognized in cores from the Dreizack Seamount area for the interval $150 \mathrm{ka}$ to present, 11 of which the author numbered, and 10 of these were associated with distinct peaks in coarse fraction lithic fragment abundance, both in glacial and interglacial horizons of the cores. Broecker's "Heinrich events" correspond to the first five or six of the IRD events originally identified by Heinrich, whereas IRD events H6, H8, H10, and H11 (+12), correlate directly with (cold) isotopic events 4.2, 5.2, 5.4, and 6.2 (+6.4), as defined in the scheme of Prell et al. [1986], and dated in the SPECMAP chronology of Imbrie et al. [1984]. All ten of the peaks in IRD sand abundance in Heinrich's original cores correlate with MS peaks in NE Atlantic cores from between $40^{\circ} \mathrm{N}$ and $60^{\circ} \mathrm{N}$, with the exception of $\mathrm{H3}$ in some instances. Where data are available, the correlation between Heinrich IRD events and significant peaks in the MS profiles of NE Atlantic cores, both within glacial and interglacial $\left(\delta^{18} \mathrm{O}\right.$ stage 5$)$ horizons, is corroborated by a clear covariance between the MS profiles and sedimentological data of the same kind as those used by Heinrich to identify IRD events in his Dreizack Seamount cores.

Using the time-slice mapping approach developed by the CLIMAP project group, it is possible to reconstruct the patterns of variation in LGM/Holocene MS-ratios in the NE Atlantic (MS value for the last glacial maximum time-slice, 18-19 ka, divided by the MS value for present-day sediment at the same site), which relate to changes in the deposition of IRD ( \pm biogenic input) between the two intervals analysed. Our MS-ratio map, based on over 80 North Atlantic and Norwegian Sea cores, confirms the existence of a dominantly cyclonic surface current gyre north of the polar front at this time. In the NE Atlantic, the gyre comprised a sluggish warm current flowing north between $45^{\circ}$ and $62^{\circ} \mathrm{N}$, which supplied numerous icebergs derived from the marine margins of the Laurentian Ice Sheet in the Labrador Sea and Nova Scotian shelf region. This iceberg laden warm current probably converged with the glacial Irminger current south of Iceland, but most or all of the icebergs it transported north melted prior to reaching the Iceland Basin. Consequently, most IRD deposition at the LGM took place in the NE Atlantic between $40^{\circ}$ and $60^{\circ} \mathrm{N}$. In the N.W. Atlantic, the gyre comprised a weak warm current flowing south along the line of the western flank of the Reykjanes Ridge, veering east in the Newfoundland Basin, and completing the cyclonic gyre in the West European Basin, northeast of the Azores. This current also transported melting icebergs derived from Iceland and possibly North European-Scandinavian sources. 
Acknowledgments. We are extremely grateful to Hartmut Heinrich for permission to reproduce \%IRD sand data from core ME69-17; to Phil Weaver for permission to use IOS carbonate, $\delta^{18} \mathrm{O}$, and stratigraphic data, and for allowing us access to IOS piston cores stored in their repository; to Rob Kidd for permission to sample the King's Trough Flank gravity cores; to Roy Chester and Herman Zimmerman for allowing us to measure the magnetic properties of the time-slice samples, and to John Sahota for his assistance in these measurements; to John King and co-workers from the University of Rhode Island for allowing us access to their unpublished magnetic susceptibility data from DSDP sites 552, 607, and 609; to Jean Claude Duplessy and Maurice Arnold for AMS ${ }^{14} \mathrm{C}$ measurements of BOFS core 5K; and to Nick Shackleton and Simon Crowhurst for provision of and assistance with installing SPECMAP spectral analysis software. We also thank the U.K. Natural Environment Research Council for financial support.

\section{References}

Alley, R.B., and D.R. MacAyeal, Ice-rafted debris associated with binge/purge oscillations of the Laurentide Ice Sheet, Paleoceanography, 9, 503-511, 1994.

Amin, B.S., S.D. Likhite, C. Radhakrishnamurty, and B.L.K. Somayajulu, Susceptibility stratigraphy and paleomagnetism of some deep Pacific Ocean cores, Deep Sea Res., 19, 249$252,1972$.

Banerjee, S.K., J.W. King, and J. Marvin, A rapid method for magnetic granulometry with applications to environmental studies, Geophys. Res. Lett., 8, 333-336, 1981.

Bascomb, C.L., Physical and chemical analyses of $<2 \mathrm{~mm}$ samples, in Soil Survey Laboratory Methods, Soil Surv. Tech. Monogr., No. 6, edited by B.W. Avery and C.L. Bascomb, pp. 14-41, Rothamsted Experimental Station, Harpenden, Herts., U.K., 1974.

Berger, W.H., Deep-sea carbonates: Pleistocene dissolution cycles, J. Foraminiferal Res., 3, 187-195, 1973.

Bloemendal, J., Paleoenvironmental implications of the magnetic characteristics of sediments from Deep-Sea Drilling Project site 514, Southeast Argentine Basin, Initial Rep. Deep Sea Drill Proj., 71, 2, 1097-1108, 1983.

Bloemendal, J., and P. deMenocal, Evidence for a change in the periodicity of tropical climate cycles $2.4 \mathrm{Myr}$ from whole-core magnetic susceptibility measurements, Nature, 342, 897-900, 1989.

Bloemendal, J., B. Lamb, and J.W. King, Paleoenvironmental implications of rock-magnetic properties of late Quaternary sediment cores from the eastern equatorial Atlantic, Paleoceanography, 3, 61-87, 1988.

Bloemendal, J., J.W. King, L. Tauxe, and J-P, Valet, Rock magnetic stratigraphy of Leg 108 sites 658, 659, 661, and 665, eastern tropical Atlantic, Proc. Ocean Drill Program, Sci. Results, 108, 415-428, 1989.

Bloemendal, J., J.W. King, F.R. Hall, and S-J. Doh, Rock magnetism late Neogene and Pleistocene deep-sea sediments: Relationship to sediment source, diagenetic processes, and sediment lithology, J. Geophys. Res., 97, 4361-4375, 1992.

Bloemendal, J., J.W. King, A. Hunt, P.B. DeMenocal, and A. Hayashida, Origin of the sedimentary magnetic record at Ocean Drilling Program sites on the Owen Ridge, western Arabian Sea, J. Geophys. Res., 98, 4199-4219, 1993.

Bond, G., et al., Evidence for massive discharges of icebergs into the North Atlantic ocean during the last glacial, Nature, 360, 245-249, 1992.
Bond, G., W. Broecker, S. Johnson, J. McManus, L. Labeyrie, J. Jouzel, and G. Bonani, Correlation between climate records from North Atlantic sediments and Greenland ice, Nature, 365, 143-147, 1993.

Booty, B. (Ed.), Status report on research at the Institute of Oceanographic Sciences related to the possible disposal of radioactive waste on or beneath the seafloor: April, 1979, to March, 1984, Rep. 204, Inst. of Oceanogr. Sci., 224 pp., Institute of Oceanographic Sciences, Wormley, Godalming, Surrey, U.K., 1985.

Boyce, R.E., and G.W. Bode, Carbon and carbonate analyses, Leg 9, Deep Sea Drilling Project, Initial Rep. Deep Sea Drill Proj., 9, 797-816, 1972.

Bradley, W.H., et al., Geology and biology of of North Atlantic deep-sea cores, U.S. Geol. Surv. Prof. Pap., 196, $163 \mathrm{pp}, 1941$.

Bramlette, M.N., and W.H. Bradley, Geology and biology of North Atlantic deep-sea cores between Newfoundland and Ireland, Pt. 1, Lithology and geologic interpretations, U.S. Geol. Surv. Prof. Pap., 196-A, 1-34, 1941.

Broecker, W.S., Calcite accumulation rates and glacial to interglacial changes in ocean mixing, in The Late Cenozoic Glacial Ages, edited by K.K. Turekian, pp. 239-265, New Haven, Yale University Press, 1971.

Broecker, W.S., G. Bond, M. Klas, E. Clark, and J. McMan us, Origin of the northern Atlantic's Heinrich events, Clim. Dyn., 6, 265-273, 1992.

Canfield, D.E., and R.A. Berner, Dissolution and pyritization of magnetite in anoxic marine sediments, Geochim. Cosmochim. Acta, 51, 645-659, 1987.

Chuey, J.M., D.K. Rea, D.K., and N.G. Pisias, Late Pleisto cene paleoclimatology of the central equatorial Pacific: A quantitative record of eolian and carbonate deposition, Quat. Res., 28, 323-339, 1987.

Clemens, S.C., and W.L. Prell, One million year record of summer monsoon winds and continental aridity from the Owen Ridge (site 722), Northwest Arabian Sea, Proc. Ocean Drill. Program, Sci. Results, 117, 365-388, 1991.

Cline, R.M., and Hays, J.D. (Editors), Investigation of late Quaternary paleoceanography and paleoclimatology, Geol. Soc. Am. Mem., 145, 464 pp., 1976.

Conolly, J.R., and M. Ewing, Pleistocene glacial marine zones in North Atlantic deep-sea sediments, Nature, 208, 135-139, 1965.

Crowley, T.J., Late Quaternary carbonate changes in the North Atlantic, and Atlantic/Pacific comparisons, in The Carbon Cycle and Atmospheric $\mathrm{CO}_{2}$ : Natural Variations, Archaen to Present, edited by E.T. Sunquist and W.S. Broecker, Geophys. Monogr. Ser., vol. 32, pp. 271-284, AGU Washington, D. C., 1985.

Dankers, P.H., Magnetic properties of dispersed natural iron oxides of known grain size, Ph.D. thesis, Univ. Utrecht, Utrecht, Netherlands, 1978.

Dean, W.E., and J.V. Gardner, Milankovitch cycles in Neog ene deep-sea sediment, Paleoceanography, 1, 539-553, 1986.

deMenocal, P., J. Bloemendal, and J.W. King, A rock-magnetic record of monsoonal dust deposition at $2.4 \mathrm{Ma}$, Proc. Ocean Drill. Program, Sci. Results, 117, 389-407, 1991.

Diester-Haass, L., Rhythmic carbonate content variations in Neogene sediments above the oceanic lysocline, in Cycles and Events in Stratigraphy, edited by G. Einsele et al., Springer-Verlag, pp. 94-108, New York, 1991.

Doh, S-J., J.W. King, and M. Leinen, A rock-magnetic study of giant piston core LL44-GPC3 from the central North Pacific, and its paleoceanographic implications, Paleoceanography, 3, 89-111, 1988. 
Dowdeswell, J., and T. Murray, Modelling rates of sedimen tation from icebergs, in Glacimarine Environments: Processes and Sediments, edited by J. Dowdeswell and J. Scourse, pp. 121-137, Spec. Publ. 53, Geological Society of London, London, 121-137, 1990.

Dreimanis, A., Quantitative gasometric determination of calcite and dolomite by using the Chittick Apparatus, J. Sediment. Petrol., 32, 520-529, 1962.

Dunlop, D.J., The rock magnetism of fine particles, Phys. Earth Planet. Inter., 26, 1-26, 1981.

Dunn, D.A., Revised techniques for quantitative calcium carbonate analysis using the "Karbonat-Bombe" and comparisons with other quantitative carbonate analysis methods, $J$. Sediment. Petrol., 50, 631-636, 1980.

Farrell, J.W., and W.L. Prell, Climatic change and $\mathrm{CaCO}_{3}$ preservation: an 800,000 year bathymetric reconstruction from the central equatorial Pacific Ocean, Paleoceanography, 4, 447-466, 1989.

Fillon, R.H., Northwest Labrador Sea stratigraphy, sand input, and paleoceanography during the last 160,000 years, in Quaternary Environments: Eastern Canadian Arctic, Baffin Bay, and Western Greenland, edited by J.T. Andrews, pp. 210-247, Allen and Unwin, Winchester, Mass., 1985.

Fillon, R.H., G.H. Miller, and J.T. Andrews, Terrigenous sand in Labrador Sea hemipelagic sediments and paleoglacial events on Baffin Island over the last 100,000 years, Boreas, 10, 107-124, 1981.

Flint, R.F., Glacial and Quaternary Geology, 892 pp., John Wiley and Sons, Inc., New York, 1971.

Gale, S.J., and P.G. Hoare, Quaternary Sediments: Petrographic Methods for the Study of Unlithified Rocks, 323 pp., John Wiley and Sons, Inc., New York, 1991.

Grötsch, J., G. Wu, and W.H. Berger, Carbonate cycles in the Pacific: reconstruction of saturation fluctuations, in Cycles and Events in Stratigraphy, edited by G. Einsele et al., pp. 110-125, Springer-Verlag, New York, 1991.

Grousset, F.E., L. Labeyrie, J.A. Sinko, M. Cremer, G. Bond, J. Duprat, E. Cortijo, and S. Huon., Patterns of ice-rafted detritus in the glacial North Atlantic $\left(40-55^{\circ} \mathrm{N}\right)$, Paleoceanography, 8, 175-192, 1993.

Haggerty, S.E., Oxidation of opaque minerals in basalts, in Oxide Minerals, edited by D. Rumble III, pp. Hg1-Hg100, Mineralogical Society of America, Washington, D.C., 1976 .

Haggerty, S.E., Opaque mineral oxides in terrestrial igneous rocks, in Oxide Minerals, edited by D. Rumble III, Hg101$\mathrm{Hg} 300$, Mineralogical Society of America, Washington, D.C., $1976 b$.

Hall, F.R., and J.W. King, Rock-magnetic stratigraphy of site 645 (Baffin Bay) from ODP leg 105, Proc. Ocean Drill. Program, Sci, Results, 105, 843-859, 1989.

Hall, F.R., W.H. Busch, and J.W. King, The relationship between variations in rock-magnetic properties and grain size of sediments from ODP Hole 645C, Proc. Ocean Drill. Program, Sci. Results, 105, 837-841, 1989.

Hall, F.R., J. Bloemendal, J.W. King, M.A. Arthur, and A.E. Aksu, Middle to late Quaternary sediment fluxes in the Labrador Sea, ODP leg 105, site 646: Synthesis of rockmagnetic, oxygen isotopic, carbonate, and planktonic foraminiferal data, Proc. Ocean Drill. Program, Sci. Results, 105, 653-665, 1989.

Heinrich, H., Origin and consequences of cyclic ice-rafting in the Northeast Atlantic Ocean during the past 130,000 years, Quat. Res, 29, 142-152, 1988.

Imbrie, J., J.D. Hays, D.G. Martinson, A. Mclntyre, A.C. Mix, J.J. Morley, N.G. Pisias, W.L. Prell, and N.J.
Shackleton, The orbital theory of Pleistocene climate: Support from a revised chronology of the marine $\delta^{18} \mathrm{O}$ record, in Milankovitch and Climate, Part 1, edited by A.L. Berger et al., pp. 269-305, D. Reidel, Norwell, Mass., 1984.

Imbrie, J., A. McIntyre, and A. Mix, Oceanic response to orbital forcing in the late Quaternary: Observational and experimental strategies, in Climate and Geosciences, edited by A. Berger et al., pp. 121-164, Kluwer Academic, Boston, Mass., 1989.

Imbrie, J., et al., On the structure and origin of major glacia tion cycles, 1, Linear responses to Milankovitch forcing, Paleoceanography, 7, 701-738, 1992.

Jenkins, G.M., and D.G Watts, Spectral Analysis and its Applications, Holden Day, San Francisco, Calif., 1968.

Kent, D.V., Apparent correlation of paleomagnetic intensity and climatic records in deep-sea sediments, Nature, 299, 538$539,1982$.

Kidd, R.B., R.C. Searle, P.P.E. Weaver, C.L. Jacobs, Q.J. Huggett, M.J. Noel, and P.J. Schultheiss, King's Trough Flank: Geological and geophysical investigations of its suitability for high-level radioactive waste disposal. IOS Rep. 166, xii +99 pp., Institute of Oceanographic Sciences, Wormley, Surrey, U.K., 1983.

King, J.W., S.K. Banerjee, J. Marvin, and O. Ozdemir, A comparison of different magnetic methods for determining the relative grain size of magnetite in natural materials: Some results from lake sediments, Earth Planet. Sci. Lett., 59, 404-419, 1982.

Kipp, N.G., New transfer function for estimating past seasurface conditions from sea-bed distribution of planktonic foraminiferal assemblages in the North Atlantic, in Investigation of Late Quaternary Paleoceanography and Paleoclimatology, edited by R.M. Cline and J.D. Hays, Geol. Soc. Am. Mem., 145, 3-41, 1976.

Kolla, V., P.E. Biscaye, and A.F. Hanley, Distribution of quartz in late Quaternary Atlantic sediments in relation to climate, Quat. Res., 11, 261-277, 1979.

Lebreiro, S.M., J.C. Moreno, I.N. McCave, and P.P.E. Weaver, Evidence of Heinrich layers off Portugal (Tore Seamount: $39^{\circ} \mathrm{N}, 12^{\circ} \mathrm{W}$ ), Mar. Geol., in press (1994).

Lancaster, D.E., 1966, Electronic metal detection, Electron. World, Dec., 39-62, 1966.

MacAyeal, D.R., A low-order model of the Heinrich event cycle, Paleoceanography, 8, 767-773, 1993a.

MacAyeal, D.R., Binge/purge oscillations of the Laurentide ice sheet as a cause of the North Atlantic's Heinrich events, Paleoceanography, 8, 775-784, 1993b.

Maher, B.A., Magnetic properties of some synthetic sub-micron magnetites, Geophys. J., 94, 83-96, 1988.

Manighetti, B., The glacial to Holocene sedimentary regime in the Northeast Atlantic ocean, Ph.D. thesis, University of Cambridge, Cambridge, U. K., 218 pp., 1993.

Maslin, M.A., A study of the paleoceanography of the NE Atlantic in the late pleistocene, $\mathrm{Ph} . \mathrm{D}$. thesis, University of Cambridge, Cambridge, U. K., 1993.

Mayer, L., N. Pisias, T. Janecek, et al., Proceedings of the Ocean Drilling Program, Initial Reports, vol. 138, Ocean Drilling Program, 1462 pp., College Station, Tex., 1992.

McCave, I.N., RRS Discovery 184 - BOFS Leg 3 Cruise Report, University of Cambridge, U.K., 1989.

McIntyre, A., N.G. Kipp, A.W.H. Bé, T. Crowley, T. Kellogg, J.V. Gardner, W. Prell, and W.F. Ruddiman, Glacial North Atlantic 18,000 years ago: a CLIMAP reconstruction, in Investigations of Late Quaternary Paleoceanography and Paleoclimatology, edited by R.M. Cline and J.D. Hays, Geol. Soc. Am. Mem., 145, 43-76, 1976. 
Mead, G.A., and L. Tauxe, Oligocene paleoceanography of the South Atlantic: Paleoclimatic implications of sediment accumulation rates and magnetic susceptibility measurements, Paleoceanography, 1, 273-284, 1986.

Molnia, B.F., Distal glacial-marine sedimentation: abundance, composition, and distribution of North Atlantic ocean Pleistocene ice-rafted sediment, in Glacial-Marine Sedimentation, edited by B.F. Molnia, pp. 593-626, Plenum, New York, 1983.

Morley, J.J., and Shackleton, N.J., The effect of accumulation rate on the spectrum of geologic time series: Evidence from two South Atlantic sediment cores, in Milankovitch and Climate, Part 1, edited by A.L. Berger et al., pp. 467-480, D. Reidel, Norwell, Mass., 1984.

Müller, G., and M. Gastner, The Karbonate-Bombe: A simple device for the determination of the carbonate content in sediment, soils, and other materials, $N$. Jhrb. Miner., Mk. 10, 466-469, 1971.

Olausson, E., Climatological, geoeconomical, and paleoceano graphic aspects of carbonate deposition, Prog. Oceanogr., 4, 245-265, 1967.

Oldfield, F., and S.G. Robinson, Geomagnetism and paleo climate, in The Climatic Scene, edited by M.J. Tooley and G.M. Sheail, pp. 186-205, Allen and Unwin, Winchester, Mass., 1985.

O'Reilly, W., Rock and Mineral Magnetism, Blackie, Glasgow, 220 pp., 1984.

Peterson, L.C., and W.L. Prell, Carbonate preservation and rates of climatic change: an $800 \mathrm{kyr}$ record from the Indian Ocean, in The Carbon Cycle and Atmospheric $\mathrm{CO}_{2}$ : Natural Variations, Archaean to Present, edited by E.T. Sundquist and W.S. Broecker, Am. Geophys. Union Monogr., 32, 251-269, 1985.

Prell, W.L., J. Imbrie, D.G. Martinson, J.J. Morley, N.G. Pisias, N.J. Shackleton, H.F. Streeter, Graphic correlation of oxygen isotope stratigraphy: Application to the late Quaternary, Paleoceanography, 1, 137-162, 1986.

Radhakrishnamurty, C., S.D. Likhite, B.S. Amin, and B.L.K. Somayajulu, Magnetic susceptibility stratigraphy in ocean sediment cores, Earth Planet. Sci. Lett., 4, 464-468, 1968.

Rea, D.K., L.W. Chambers, J.M. Chuey, T.R. Janecek, M. Leinen, and N.G. Pisias, A 420,00-year record of cyclicity in oceanic and atmospheric processes from the eastern equatorial Pacific, Paleoceanography, 1, 577-586, 1986.

Robinson, S.G., Two applications of mineral-magnetic tech niques to deep-sea sediment studies, Geophys. J.R. astron. Soc., 69, 294, 1982.

Robinson, S.G., The late Pleistocene paleoclimatic record of North Atlantic deep-sea sediments revealed by mineralmagnetic measurements, Phys. Earth Planet. Inter., 42, 2247, 1986.

Robinson, S.G., Mineral-magnetism of deep-sea sediments: Paleoclimatic implications, Ph.D. thesis, University of Liverpool, Liverpool, U. K., 1986.

Robinson, S.G., Applications for whole-core magnetic susceptibility measurements of deep-sea sediments: Leg 115 results, Proc. Ocean Drill. Program, Sci. Results, 115, edited by R.A. Duncan, J. Backman, and L.C. Peterson, College Station, TX (Ocean Drilling Program), 737-771, 1990.

Robinson, S.G., Lithostratigraphic applications for magnetic susceptibility logging of deep-sea sediment cores: Examples from ODP leg 115, in High Resolution Stratigraphy, edited by E.A. Hailwood and R.B. Kidd, pp. 65-98, Spec. Publ. 70, Geological Society of London, London, 1993

Robinson, S.G., and J. Bloemendal, The application of mineral- magnetic measurements to deep-sea sediments: some preliminary results, EOS Trans. AGU, 64, 241, 1983.

Robinson, S.G., and I.N. McCave, Orbital forcing of bottom current enhanced sedimentation on Feni Drift, NE Atlantic, during the mid-Pleistocene, Paleoceanography, 9, 943-972, 1994.

Ruddiman, W.F., North Atlantic ice-rafting: A major change at 75,000 years before the present, Science, 196, 1208-1211, $1977 \mathrm{a}$.

Ruddiman, W.F., Late Quaternary deposition of ice-rafted sand in the subpolar North Atlantic (lat $40^{\circ}$ to $65^{\circ} \mathrm{N}$ ), Geol. Soc. Am. Bull., 88, 1813-1827, 1977.

Ruddiman, W.F., and L.K. Glover, Vertical mixing of icerafted volcanic ash in North Atlantic sediments, Geol. Soc. Am. Bull., 83, 2817-2836, 1972.

Ruddiman, W.F., and A. McIntyre, Time-transgressive deglacial retreat of polar water from the North Atlantic, Quat. Res., 3, 117-130, 1973.

Ruddiman, W.F., and A. McIntyre, Northeast Atlantic paleo climatic changes over the last 600,000 years, in Investigation of Late Quaternary Paleoceanography and Paleoclimatology, edited by R.M. Cline and J.D. Hays, Geol. Soc. Am. Mem., 145, 111-146, 1976.

Ruddiman, W.F., and A. McIntyre, The North Atlantic ocean during the last deglaciation, Palaeogeog. Palaeoclimatol. Palaeoecol., 35, 145-214, 1981.

Sager, W.W., and S.A. Hall, Magnetic properties of black mud turbidites from OFP Leg 116, distal Bengal Fan, Indian Ocean, Proc. Ocean Drill. Program, Sci. Results, 116, 317$335,1990$.

Shackleton, N.J., and Hall, M.A., Oxygen and carbon isotope stratigraphy of Deep Sea Drilling Project hole 552A: PlioPleistocene glacial history, Initial Rep. Deep Sea Drill. Project, 81., 599-609, 1984.

Shackleton, N.J., E. Thomas, C. Bertram, M.A. Maslin, Global changes over the last 30,000 years: Cambridge contributions, final report for project EPOC 90-004, University of Cambridge, Cambridge, U. K., 1993.

Simet, C., M.A. Maslin, C. Hemleben, Drastic changes in the NE Atlantic deep-sea sediments and faunas: preservation patterns of calcium carbonate during the last 150,000 years (Part 2), in Short and Long Term Global Change: Records and Modelling, Proc. ICP IV, edited by M. Sarnthein, J. Theide, and R. Zahn, GEOMAR Rep. 15, University of Kiel, Kiel, Germany, 1992.

Smythe, F.W., Jr., W.F. Ruddiman, and D.N. Lumsden, Icerafted evidence of long-term North Atlantic circulation, Mar. Geol., 64, 131-141, 1985.

Somayajulu, B.L.K., C. Radhakrishnamurty, and T.J. Walsh, Magnetic susceptibility stratigraphy of Pacific Pleistocene sediments, Nature, 253, 616-617, 1975.

Thompson, R. , and F. Oldfield, Environmental Magnetism, 227 pp., Allen and Unwin, Winchester, Mass., 1986.

Volat, J-L., L. Pastouret, and C. Vergnaud-Grazzini, Dissol ution and carbonate fluctuations in Pleistocene deep-sea cores: a review, Mar. Geol., 34, 1-28, 1980.

Weaver, P.P.E., An integrated stratigraphy of the Upper Quaternary of the King's Trough Flank area, NE Atlantic, Oceanol. Acta., 6, 451-456, 1983.

Weaver, P.P.E., and P.J. Schultheiss, Detection of repenetrat ion and sediment disturbance in open-barrel gravity cores, $J$. Sediment. Petrol., 53, 649-678, 1983.

Zimmerman, H.B., Fine grained sediment distribution in the late Pleistocene/Holocene North Atlantic, Bull. Inst. Géol. Bassin d'Aquitaine, Bordeaux, 31, 337-357, 1982. 
Zimmerman, H.B., N.J. Shackleton, J. Backman, D.V. Kent, J.G. Baldauf, A.J. Kaltenback, and A.C. Morton, History of Plio-Pleistocene climate in the Northeastern Atlantic, DeepSea Drilling Project Hole 552A, Initial Rep. Deep Sea Drill. Proj., 81, 861-875, 1984.

M. A. Maslin, Department of Geography, University College London, 26 Bedford Way, London, WC1H 0AP, England, United Kingdom.

I. N. McCave, Department of Earth Sciences, University of
Cambridge, Downing Street, Cambridge, CB2 3EQ, England, United Kingdom.

S. G. Robinson, Department of Environmental and Geographical Sciences, Manchester Metropolitan University, John Dalton Building, Chester Street, Manchester, M1 5GD, England, United Kingdom.

(Received April 28, 1994; revised October 6, 1994; accepted October 7, 1994) 